This is a postprint of an article published by Elsevier. The final version of Irma Flores, Antxon Martínez de Ilarduya, Haritz Sardon, Alejandro J. Müller, Sebastian Muñoz-Guerra, ROP and crystallization behaviour of partially renewable triblock aromatic-aliphatic copolymers derived from L-lactide, European Polymer Journal, (2020), 122, article id 109321, is available at https://doi.org/10.1016/j.eurpolymj.2019.109321 @2019 This manuscript version is made available under the CC-BY-NC-ND 4.0 license http://creativecommons.org/licenses/by-nc-nd/4.0/

\title{
ROP and crystallization behaviour of partially renewable triblock aromatic-aliphatic copolymers derived from L-Lactide.
}

\author{
Irma Flores ${ }^{1}$, Antxon Martínez de llarduya ${ }^{3 *}$, Haritz Sardon ${ }^{1^{*}}$, Alejandro J. Müller ${ }^{1,2^{*}}$ \\ and Sebastian Muñoz-Guerra³.
}

${ }^{1}$ POLYMAT and Polymer Science and Technology Department, Faculty of Chemistry, University of the Basque Country UPV/EHU, Paseo Manuel de Lardizabal 3, 20018, Donostia-San Sebastián, Spain.

${ }^{2}$ IKERBASQUE, Basque Foundation for Science, Bilbao, Spain.

${ }^{3}$ Departament d'Enginyeria Química, Universitat Politècnica de Catalunya, ETSEIB, Diagonal 647, 08028 Barcelona, Spain

\footnotetext{
*Corresponding authors: antxon.martinez.de.ilarduia@upc.edu, haritz.sardon@ehu.es and alejandrojesus.muller@ehu.es
} 


\section{ABSTRACT}

Two series of partially biobased ABA triblock copolyesters were successfully prepared by ring-opening polymerization (ROP) of $L$-lactide initiated by two telechelic polyester polyols using an organic catalyst. B blocks were made of telechelic poly(hexamethylene terephthalate) (PHT) and poly(hexamethylene 2,5furandicarboxylate) (PHF), respectively, with average molar masses of around $3500 \mathrm{~g}$ $\mathrm{mol}^{-1}$ and $\mathrm{A}$ blocks were made of poly(lactic acid)s (PLA) of different block lengths.

For each series, four copolymers with different PHT/PLA and PHF/PLA compositions were prepared by varying the feed molar ratios. The triblock structure of the obtained copolymers was ascertained by ${ }^{13} \mathrm{C} N \mathrm{NM}$, which confirms that the organic catalyst employed does not promote transesterification reactions at the low temperatures used for the reaction. All copolyesters were thermally stable under inert atmosphere up to around $300{ }^{\circ} \mathrm{C}$. For all synthesized copolyesters, the PLA blocks were unable to crystallize, mainly due to racemization reactions taking place during L-lactide ROP. Both, PHT and PHF blocks were able to crystallize and their thermal and structural properties ( $T_{\mathrm{m}}, T_{\mathrm{c}}, X_{\mathrm{c}}$ and lamellar thickness) were independent on PLA content until its concentration was very high and topological restrictions difficulted crystallization. According to SAXS, most copolymers were found to be miscible in the melt. Both PLA- $b$ PHT- $b$-PLA or PLA- $b$-PHF- $b$-PLA triblock copolymers showed a single $T_{\mathrm{g}}$ indicating that the components are miscible in the amorphous state.

Keywords: triblock copolymers, organocatalysis, biobased, poly(lactide). 


\section{Introduction}

The concern for the current environmental conditions and especially for those caused by the contamination of plastics has generated interest in the production of biodegradable and/or biobased polymers. ${ }^{1}$ This kind of polymers reduces the environmental footprint caused by the manufacture of plastics. Additionally, at the end of their life cycle, many of them tend to disintegrate (due to environmental factors such as oxygen, sunlight, rain, humidity, microorganisms) or are integrated into biomass as composting material, and this helps to reduce the amount of plastic waste accumulated in landfills. ${ }^{1}$

In this sense, poly(lactic acid) (PLA) is one of the polymers that have gained large popularity because it is biobased, biodegradable and has good properties for important applications, such as packaging. ${ }^{1-4}$ However, in many cases, the properties of PLA do not match the requirements for certain applications, and therefore several studies have focused on improving its mechanical properties. This can be achieved by mixing PLA with other polymers or by copolymerization, offering the opportunity to adapt the final properties of the materials. ${ }^{4}$

Ring-Opening Polymerization (ROP) is the method of choice for the preparation of polyesters from small lactones or macrolactones. ${ }^{5-8}$ Although this procedure has been used for the synthesis of a great diversity of polymers, its application to the preparation of aromatic-aliphatic polyesters has been less studied. The milder reaction conditions required and the minimization of undesirable byproducts, are advantages of ROP over conventional polycondensation. ${ }^{9}$ Thus, Muñoz-Guerra et al. employed this method for the preparation of random copolymers based on PHT-CO-PCL. ${ }^{10}$ In this sense, it is believed that ROP could be highly suitable to obtain well defined aliphatic-aromatic block copolyesters based on PLA. ${ }^{11-13}$

The use of PLA in block copolymers is reported in various works; for example, PLA is copolymerized with other aliphatic polyesters to improve its mechanical properties. Block copolymers of PLA with other polymers can be used as phase compatibilizers in immiscible polymer blends of PLA and aromatic polyesters (e.g., for PLA and PET (polyethylene terephthalate) blends, or PLA and PBT (polybutylene 
terephthalate) blends). ${ }^{14}$ Immiscible blends tend to display poor mechanical properties. Therefore, the addition of these copolymers would make the phases present in the mixture compatible with each other and improve their properties by reducing interfacial tension and regulating the morphology. Several examples have been reported in the literature: 1) PLA/Polyethylene (PE) immiscible blends, for which the tensile and impact resistance were significantly improved by using diblock copolymers of PLA- $b$-PE as compatibilizers. ${ }^{15}$ 2) PLA/Poly( $\varepsilon$-caprolactone)(PCL) immiscible blends compatibilized by PLA- $b$-PCL diblock and ABA triblock copolymers. ${ }^{16}$ 3) Immiscible blends of PLA/natural rubber(NR) compatibilized by a diblock copolymer from hydroxyl telechelic natural rubber (NR) and PLA. ${ }^{17}$ 4) Several works have reported block copolymers of PLA combined with PEO (polyethylene oxide) or isoprene, among others. ${ }^{14,18,19}$

Poly(hexamethylene terephthalate) (PHT) is an aromatic polyester with good mechanical properties and chemical resistance, and it can be prepared by melt polycondensation or by entropically driven ROP of macrocycles by enzymes. ${ }^{20,21}$ The presence of the flexible hexamethylene segment in the polyester chain induces a relatively low melting temperature $\left(140{ }^{\circ} \mathrm{C}\right)$, which could be an advantage during material processing and for ROP. ${ }^{20,22}$ On the other hand, poly (hexamethylene 2,5furandicarboxylate) (PHF), has similar properties to $\mathrm{PHT}$, together with the advantage of being a polymer derived partially from renewable sources. Due to its good properties, this polymer can be used in some applications where polyesters such as polyterephthalates are usually employed. ${ }^{23-25}$ While their polymerization was demonstrated, the ability to obtain well defined telechelic low molecular weight polyesters that can be further employed for the ROP of lactones has been scarcely studied.

In this work, ABA triblock copolymers were synthesized using a metal-free approach. First, telechelic polyester diols were obtained; these macro-initiators were further employed for the ROP of L-Lactide to obtain triblock copolymers with different PLA contents. The thermal behavior of the materials was analyzed to understand the effect of the composition of PLA- $b$-PHT- $b$-PLA or PLA- $b$-PHF- $b$-PLA on the properties of the obtained copolymers. 


\section{Experimental}

Materials

(3S)-cis-3,6-Dimethyl-1,4-dioxane-2,5-dione (L-lactide, 98\%) and 1,5,7triazabicyclo[4.4.0]dec-5-ene (TBD, 98\%) were purchased from Sigma-Aldrich. Methanol $\left(\mathrm{CH}_{3} \mathrm{OH}, 99.8 \%\right)$, Dichloromethane (DCM, $\left.99.5 \%\right)$ and Chloroform $\left(\mathrm{CHCl}_{3}, 98.5 \%\right)$ were supplied from Labkem. Benzoic Acid (99.5\%) was provided by Panreac.

Telechelic oligomers of poly(hexamethylene terephthalate) (PHT) and poly(hexamethylene 2,5-furandicarboxylate) (PHF) were previously synthesized following the procedure reported by Flores et al., by ring-opening polymerization of macrocyclic oligoesters. ${ }^{21}$

Synthesis of PLA-b-PHF-b-PLA and PLA-b-PHT-b-PLA Triblock Copolymers

PLA- $b$-PHF- $b$-PLA copolymers were synthesized in a round bottom flask equipped with a magnetic stirrer, where the PHF telechelic oligomer (1 eq., $1.26 \mathrm{mmol}$ of $\mathrm{HF}$ repeating units, $300 \mathrm{mg}$ ) and TBD as catalyst ( $5 \mathrm{~mol} \%$ with respect to $L$-lactide) were mixed with each one of the following amounts of L-lactide, with the intention of obtaining different compositions of PHF/PLA, these amounts were: (1 eq., $1.26 \mathrm{mmol}$, $182 \mathrm{mg}$ ), (2 eq., $2.52 \mathrm{mmol}, 363 \mathrm{mg}$ ) and (4 eq., $5.04 \mathrm{mmol}, 726 \mathrm{mg}$ ). Then DCM $\left[m l D C M=\frac{m m o l(L-\text { lactide })}{1 M}\right]$ was added and all components were mixed at $25^{\circ} \mathrm{C}$ for 5 min. After that benzoic acid $(50 \mathrm{mg}$ ) was added to stop the reaction while stirring continued for $5 \mathrm{~min}$. Then chloroform was added and the polymer obtained was precipitated in excess methanol and collected by centrifugation. Finally, the product was dried under vacuum. NMR experiments were performed to corroborate the chemical structure and microstructure of the copolymers.

Employing the same procedure previously described, PLA- $b-$ PHT- $b$-PLA copolymers were also obtained. The reagents used were the telechelic PHT oligomer (1 eq., $1.20 \mathrm{mmol}$ of $\mathrm{HT}$ repeating units, $300 \mathrm{mg}$ ), TBD catalyst ( $5 \mathrm{~mol} \%$ with respect to $L-$ lactide) and different amounts of L-lactide: (1 eq., $1.20 \mathrm{mmol}, 174 \mathrm{mg}$ ), (2 eq., 2.42 $\mathrm{mmol}, 348 \mathrm{mg}$ ) and (4 eq., $4.84 \mathrm{mmol}, 697 \mathrm{mg}$ ). 
To complement the study, reactions with a large amount of L-lactide were carried out, following the same procedure described, but with the quantities of reagents that are mentioned below, to obtain PLA- $b$-PHF- $b$-PLA: PHF telechelic oligomer (1 eq., $0.42 \mathrm{mmol}$ of HF repeating units, $100 \mathrm{mg}$ ), TBD ( 5 mol\% with respect to $L$-lactide) and $L$ lactide (16 eq., $6.72 \mathrm{mmol}, 969 \mathrm{mg}$ ); for the case of PLA- $b$-PHT- $b$-PLA the quantities used were: PHT telechelic oligomer (1 eq., $0.40 \mathrm{mmol}$ of HT repeating units, $100 \mathrm{mg}$ ), TBD (5 mol\% with respect to $L$-lactide) and $L$-lactide (16 eq., $6.45 \mathrm{mmol}, 930 \mathrm{mg}$ ).

PLA- $\boldsymbol{b}$-PHF- $\boldsymbol{b}$-PLA: ${ }^{1} \boldsymbol{H}$ NMR (300.1 MHz, $\left.\mathrm{CDCl}_{3}, \delta(\mathrm{ppm})\right): 7.19(\mathrm{~s}, \mathrm{ArH}), 5.16(\mathrm{~m}, \mathrm{CH}(\mathrm{LA}))$, 4.34 (t, $\left.\mathrm{OCH}_{2}(\mathrm{HF})\right), 1.79\left(\mathrm{~m}, \mathrm{OCH}_{2} \mathrm{CH}_{2}(\mathrm{HF})\right), 1.58$ (d, $\left.\mathrm{CH}_{3}(\mathrm{LA})\right), 1.48\left(\mathrm{~m}, \mathrm{OCH}_{2} \mathrm{CH}_{2} \mathrm{CH}_{2}\right.$ (HF)). ${ }^{13} \mathrm{C} \mathrm{NMR} \mathrm{(75.5} \mathrm{MHz,} \mathrm{CDCl} 3$, $\delta$ (ppm)): 169.6 (CO (LA)), 158.1 (CO (HF)), 146.9 (ArC (HF)), 118.3 (ArCH (HF)), 69.3 (CH (LA)), $65.4\left(\mathrm{OCH}_{2}(\mathrm{HF})\right), 28.5\left(\mathrm{OCH}_{2} \mathrm{CH}_{2}(\mathrm{HF})\right), 25.5$ $\left(\mathrm{OCH}_{2} \mathrm{CH}_{2} \mathrm{CH}_{2}(\mathrm{HF})\right)$, $16.6\left(\mathrm{CH}_{3}(\mathrm{LA})\right)$.

PLA- $b$-PHT-b-PLA: ${ }^{1} H$ NMR (300.1 MHz, CDCl 3 , $\delta$ (ppm)): 8.08 (s, ArH), 5.17 (m, CH (LA)), 4.36 (t, $\left.\mathrm{OCH}_{2}(\mathrm{HT})\right), 1.82\left(\mathrm{~m}, \mathrm{OCH}_{2} \mathrm{CH}_{2}(\mathrm{HT})\right), 1.58$ (d, $\left.\mathrm{CH}_{3}(\mathrm{LA})\right), 1.54\left(\mathrm{~m}, \mathrm{OCH}_{2} \mathrm{CH}_{2} \mathrm{CH}_{2}\right.$ (HT)). ${ }^{13} \mathrm{C} \mathrm{NMR}\left(75.5 \mathrm{MHz}, \mathrm{CDCl}_{3}, \delta(\mathrm{ppm})\right): 169.6$ (CO (LA)), 165.8 (CO (HT)), 134.1 (ArC (HT)), 129.5 ( $\mathrm{ArCH}(\mathrm{HT})), 69.0(\mathrm{CH}(\mathrm{LA})), 65.3\left(\mathrm{OCH}_{2}(\mathrm{HT})\right), 28.6\left(\mathrm{OCH}_{2} \mathrm{CH}_{2}(\mathrm{HT})\right), 25.7$ $\left(\mathrm{OCH}_{2} \mathrm{CH}_{2} \mathrm{CH}_{2}(\mathrm{HT})\right)$, $16.6\left(\mathrm{CH}_{3}(\mathrm{LA})\right)$.

\section{Characterization}

NMR Spectroscopy

${ }^{1} \mathrm{H}$ NMR and ${ }^{13} \mathrm{C}$ NMR spectra were recorded at 300.1 and $75.5 \mathrm{MHz}$, respectively, on a Bruker AMX-300 NMR instrument. For NMR analysis, polymers were dissolved in deuterated chloroform $\left(\mathrm{CDCl}_{3}\right)$ containing a small amount of TMS internal reference. About 10 and $40 \mathrm{mg}$ of sample in $0.7 \mathrm{~mL}$ deuterated solvent were used for ${ }^{1} \mathrm{H} N M R$ and ${ }^{13} \mathrm{C}$ NMR respectively. 
Gel Permeation Chromatography (GPC)

A Waters equipment fitted with RI and UV detectors, was used to measure molecular weights of the polymers obtained. HR5E and HR2 Waters linear Styragel columns (7.8 mm $\times 300 \mathrm{~mm}$, pore size 103-104 Å) packed with crosslinked polystyrene and protected with a precolumn were used. For each sample, $100 \mu \mathrm{L}$ of $0.1 \%(\mathrm{w} / \mathrm{v})$ sample solution was injected and chromatographed with a flow of $0.4 \mathrm{~mL} \mathrm{~min}^{-1}$. Molar mass averages were calculated against PMMA standards.

Differential Scanning Calorimetry (DSC)

The thermal transitions of the polymers were analyzed by differential scanning calorimetry (DSC), employing a DSC 8500 (PerkinElmer). The DSC scans were measured employing 4.5-5.5 mg samples at heating and cooling rates of $20^{\circ} \mathrm{C} / \mathrm{min}$ from -30 to 200 ${ }^{\circ} \mathrm{C}$ under a nitrogen flow of $20 \mathrm{~mL} / \mathrm{min}$. The instrument was calibrated with indium and tin standards. The melting peak temperature $\left(T_{m}\right)$ and the latent heat of melting $\left(\Delta H_{m}\right)$ reported in the results section are taken from the second heating scans. The glass transition temperatures $\left(T_{g}\right)$ were determined with a heating rate of $40{ }^{\circ} \mathrm{C} / \mathrm{min}$ after rapidly quenching the sample (employing the instrument ballistic cooling setting that produces a nominal cooling rate of $120^{\circ} \mathrm{C} / \mathrm{min}$ approximately).

Thermogravimetric Analysis (TGA)

Weight loss as a function of temperature was examined by a TGA Q500 (TA instrument) under a nitrogen atmosphere. Samples of 5-10 mg were heated from 40 to $600^{\circ} \mathrm{C}$ at a rate of $10{ }^{\circ} \mathrm{C} / \mathrm{min}$.

Simultaneous Wide-Angle and Small-Angle X-ray Scattering (SAXS/WAXS)

The samples were placed in capillaries and after examined under non-isothermal condition by simultaneous WAXS/SAXS performed at beamline BL11-NCD at the ALBA Synchrotron radiation facility (Barcelona, Spain). In a Linkam THMS600 stage coupled to 
a liquid nitrogen cooling system, the patterns were collected by cooling from $180^{\circ} \mathrm{C}$ to $-30{ }^{\circ} \mathrm{C}$ and subsequently heating from $-30{ }^{\circ} \mathrm{C}$ to $180{ }^{\circ} \mathrm{C}$ at a rate of $20^{\circ} \mathrm{C} / \mathrm{min}$. The energy of the X-ray source was $12.4 \mathrm{keV}(\lambda=1.0 \AA$ ). Using a Rayonix LX255-HS detector with an active area of $85 \times 255 \mathrm{~mm}^{2}$ (pixel size $40 \times 40 \mu \mathrm{m}^{2}$ ), where the sample-to-detector distance employed was $196.14 \mathrm{~mm}$ with a detector tilt angle of $30.33^{\circ}$, the WAXS patterns were measured. On the other hand, employing Pilatus $1 \mathrm{M}$ detector (from Dectris), with an active area of $168.7 \times 179.4 \mathrm{~mm}^{2}$ (pixel size $172 \times 172 \mu \mathrm{m}^{2}$ ), where the sample-to-detector distance employed was $6790 \mathrm{~mm}$ with a detector tilt angle of $0^{\circ}$, the SAXS patterns were collected. The intensity profile was output as a plot of the scattering intensity vs. scattering vector. The scattering vector was calibrated using silver behenate (SAXS) and chromium (III) oxide (WAXS). 


\section{Results and discussion}

Synthesis of Triblock Copolymers

In this work, the triblock copolymers were synthesized using TBD as catalyst, due to the effectiveness shown by this catalyst to copolymerize LA with other monomers maintaining low transesterification. ${ }^{26,27}$ Due to the above, it is expected that the TBD has a catalytic activity that promotes the formation of triblock copolymers (PLA- $b$-PHT$b$-PLA and PLA- $b$-PHF- $b$-PLA).

First, the oligomers derived from HT or HF were synthesized according to the procedure described by Flores et al. ${ }^{10}$. Telechelics from $\mathrm{HT}$ and $\mathrm{HF}$ were obtained by ROP of cyclic oligoesters previously prepared by enzymatic cyclization using CALB as catalyst, and a diol (1,6 Hexanediol) as initiator (1/12 ratio). The polymerization of both telechelics was confirmed by ${ }^{1} \mathrm{H} N \mathrm{NM}$, and their characteristic peaks are assigned in Figures 1 and 2.

Ar:<smiles></smiles><smiles>CC(C)OCCCCCCOC(=O)[Te]C(=O)OCCCCCCO</smiles><smiles>CC(C)OC(C)C(=O)OC(C)C(=O)OCCCCCCOC(=O)C(C)(C)C(=O)[Te]C(=O)OCCCCCCOC(C)(C)C(=O)C(C)OC(C)C</smiles>

Scheme 1. Synthesis of Triblock Copolymers. 
The obtained telechelic macro-initiators have a theoretical number average molecular weight of 3,000. The experimental molecular weight determined by end group analysis by NMR is similar to the theoretical one. After this characterization that corroborated the formation of low molecular weight telechelic polyester diols, the corresponding oligomers (PHT or PHF) were used as initiator for the ring-opening polymerization of $L$-lactide in the presence of the TBD catalyst. Because the telechelic oligomer has two hydroxyl end groups, the final copolymer is expected to have an ABA triblock structure (Scheme 1), if no transesterification takes place during the ROP process.
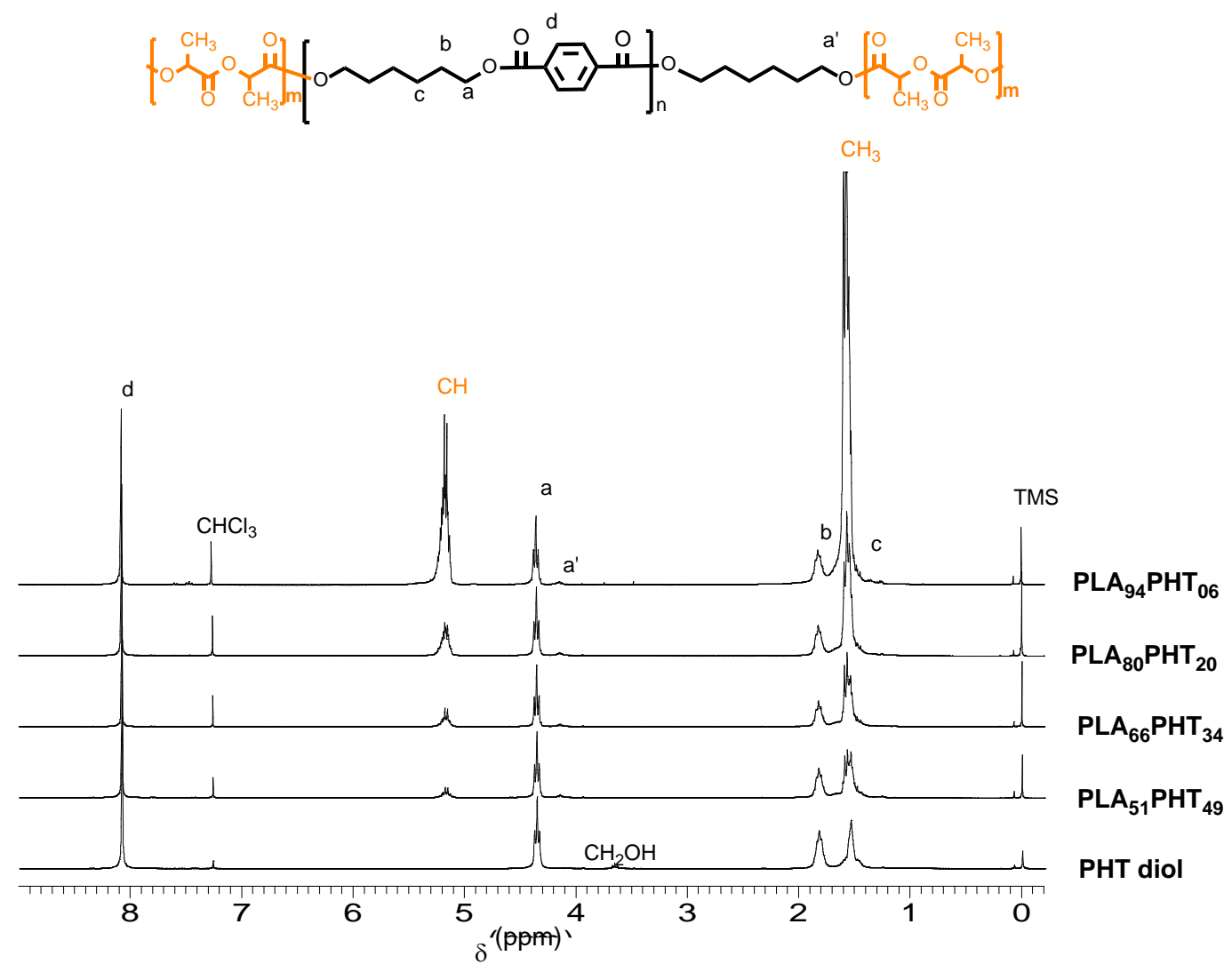

Figure 1. ${ }^{1} \mathrm{H}$ NMR spectra of PHT diol and PLA- $b$-PHT- $b$-PLA copolyesters with peak assignments.

The copolymerization reaction was followed by both GPC and NMR. ${ }^{1} \mathrm{H}$ NMR spectra of PLA- $b$-PHAr- $b$-PLA triblock copolymers (Figures 1 and 2) revealed that the hydroxyl end groups of the telechelic oligomers acted as initiators in the ROP of $L$-lactide. Signals corresponding to the methylene end groups of PHT and PHF downfield shifted as a consequence of the esterification reaction taking place with the lactide monomer. 
No signals were observed at $3.7 \mathrm{ppm}$ for both series indicating that all end groups initiated the ROP of lactide monomer.

The copolymer composition (Table 1) was determined by integration of signals appearing at $5.15 \mathrm{ppm}$ corresponding to the methine protons of lactic acid units and signals appearing at around 4.30 and $4.15 \mathrm{ppm}$ corresponding to a and a' methylenes respectively of the hexamethylene furanoate and hexamethylene terephthalate units.
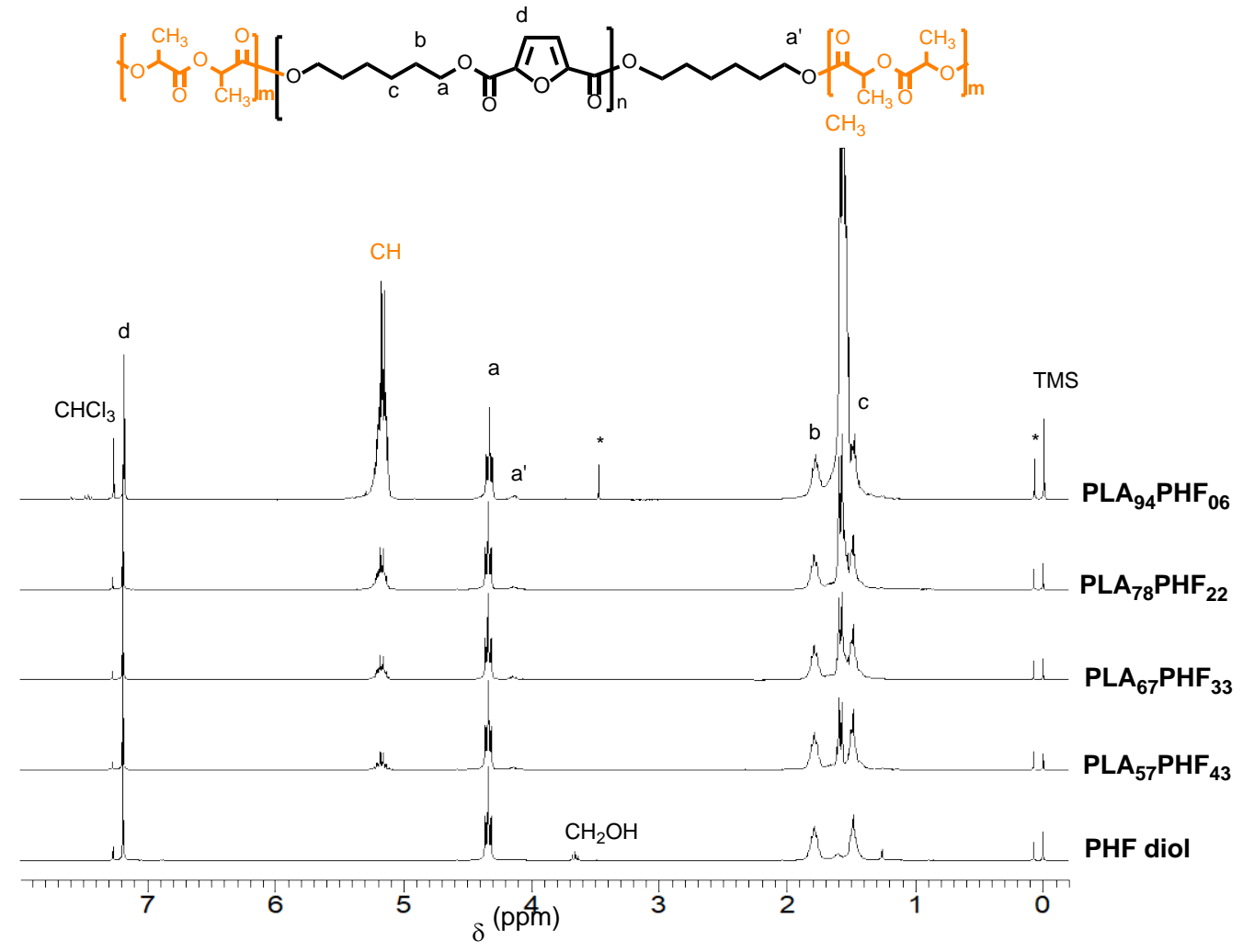

Figure 2. ${ }^{1} \mathrm{H}$ NMR spectra of PHF diol and PLA- $b$-PHF- $b$-PLA copolyesters with peak assignments. $\left(^{*}\right)$ Signals of methanol and silicon oil impurities. 


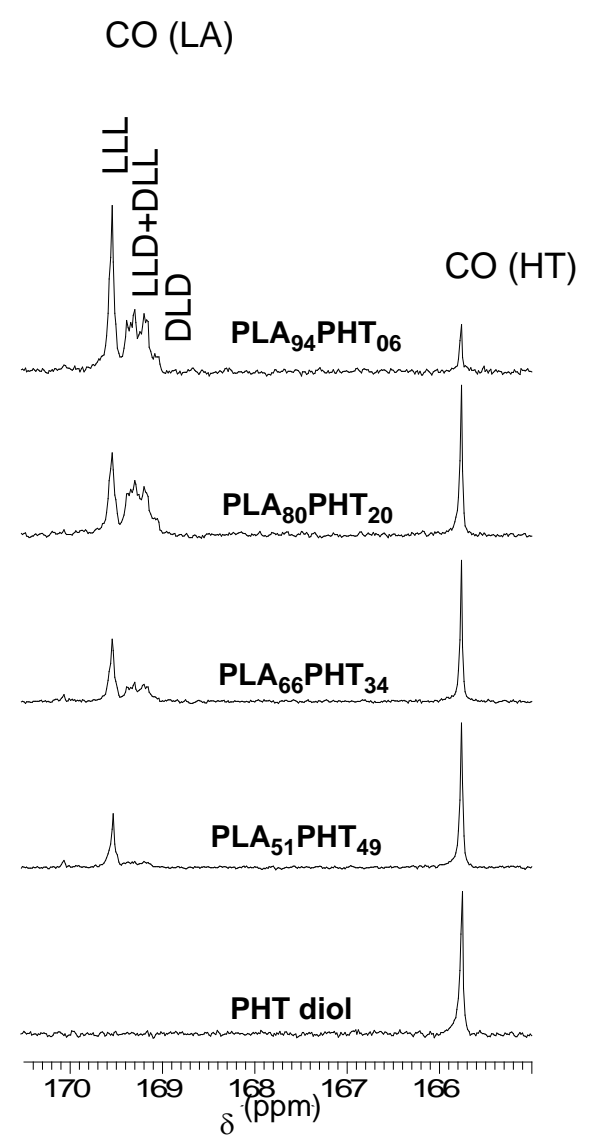

a)

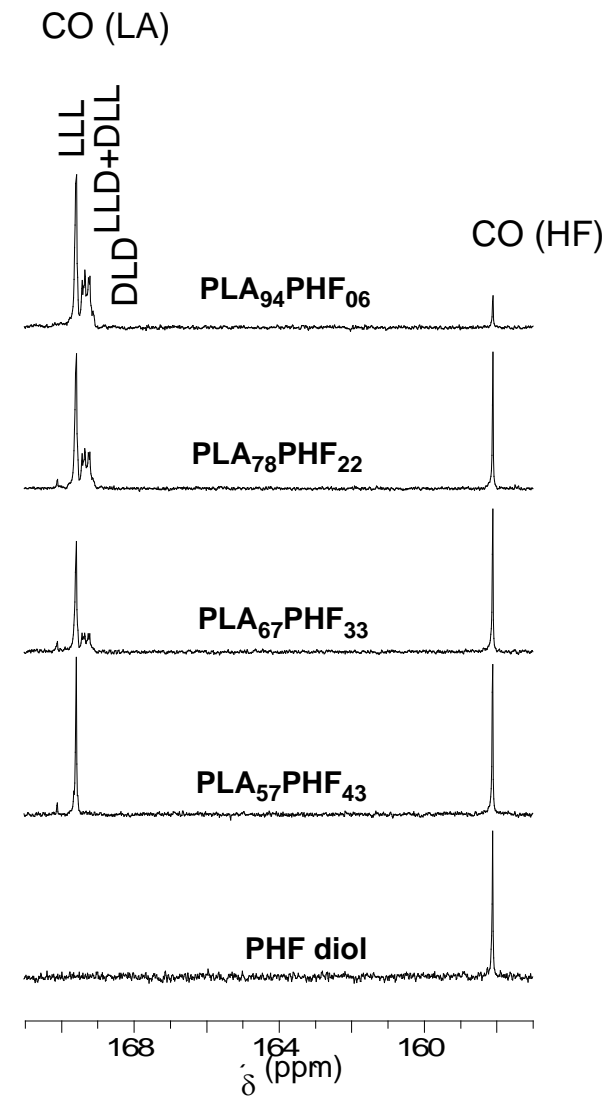

b)

Figure $3 .{ }^{13} \mathrm{C}$ NMR spectra of a) PHT diol and PLA- $b$-PHT- $b$-PLA copolyesters and b) PHF diol and PLA-b-PHF- $b$-PLA copolyesters in the region of carbonyl peaks.

In order to confirm the triblock structure of the copolymers obtained, ${ }^{13} \mathrm{C} N \mathrm{NM}$ spectra were carried out for both series. Figures S1 and S2 (see Supporting Information), show ${ }^{13} \mathrm{C}$ NMR spectra for PLA- $b$-PHAr- $b$-PLA copolymers with peak assignments. As it is well documented, carbonyl groups, as well as non-protonated aromatic carbons, are very sensitive to sequence distributions. ${ }^{28}$ In the spectra of both series, signals due to carbonyl groups of PHT and PHF blocks appear as single peaks (Figure 3), which indicates that no transesterification took place during ROP of $L$-lactide initiated by the telechelic PHT and PHF macro-initiators. On the other hand, the carbonyl signal of PLA blocks is split, due to monomer racemization during polymerization. ${ }^{29}$ This splitting was more evident as the molecular weight increased or triblock copolymer was enriched in lactic acid units. 
Table 1 Composition, molecular weight and block lengths of synthesized materials

\begin{tabular}{|c|c|c|c|c|c|c|c|c|c|}
\hline \multirow{3}{*}{ Sample } & \multicolumn{6}{|c|}{ NMR } & \multicolumn{3}{|c|}{ GPC } \\
\hline & \multicolumn{2}{|c|}{$\%$ mass ratio } & \multicolumn{2}{|c|}{$\%$ mol ratio } & \multirow{2}{*}{ L-PHT-L ${ }^{a}$} & \multirow{2}{*}{$M_{n}$} & \multirow{2}{*}{$M_{n}$} & \multirow{2}{*}{$M_{w}$} & \multirow{2}{*}{$\boldsymbol{\oplus}$} \\
\hline & $H T$ & Lactic & $H T$ & Lactic & & & & & \\
\hline Telechelic PHT & 100 & - & 100 & - & 14 & 3300 & 1650 & 3600 & 2.2 \\
\hline $\mathrm{PLA}_{51} \mathrm{PHT}_{49}$ & 77 & 23 & 49 & 51 & 07:14:07 & 4400 & 3650 & 6750 & 1.8 \\
\hline $\mathrm{PLA}_{66} \mathrm{PHT}_{34}$ & 64 & 36 & 34 & 66 & $14: 14: 14$ & 5350 & 4750 & 9150 & 1.9 \\
\hline $\mathrm{PLA}_{80} \mathrm{PHT}_{20}$ & 46 & 54 & 20 & 80 & $28: 14: 28$ & 7550 & 7400 & 12650 & 1.8 \\
\hline \multirow[t]{2}{*}{$\mathrm{PLA}_{94} \mathrm{PHT}_{06}$} & 18 & 82 & 06 & 94 & $110: 14: 110$ & 19300 & 18800 & 29000 & 1.5 \\
\hline & $H F$ & Lactic & $H F$ & Lactic & L-PHF-L & & & & \\
\hline Telechelic PHF & 100 & - & 100 & - & 16 & 3900 & 4750 & 10500 & 2.2 \\
\hline $\mathrm{PLA}_{57} \mathrm{PHF}_{43}$ & 71 & 29 & 43 & 57 & $11: 16: 11$ & 5440 & 7050 & 12250 & 1.7 \\
\hline $\mathrm{PLA}_{67} \mathrm{PHF}_{33}$ & 62 & 38 & 33 & 67 & $16: 16: 16$ & 6350 & 8300 & 13000 & 1.6 \\
\hline $\mathrm{PLA}_{78} \mathrm{PHF}_{22}$ & 48 & 52 & 22 & 78 & $30: 16: 30$ & 8400 & 9650 & 15600 & 1.6 \\
\hline $\mathrm{PLA}_{94} \mathrm{PHF}_{06}$ & 17 & 83 & 06 & 94 & $116: 16: 116$ & 20200 & 22600 & 31800 & 1.4 \\
\hline
\end{tabular}

${ }^{a}$ Number of L units [poly(lactic acid)] and number of repeat units of PHT or PHF present in the blocks.

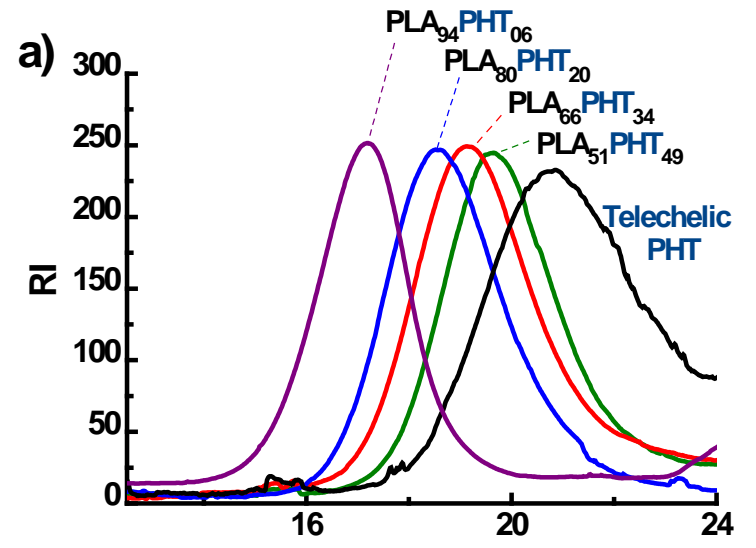

Retention Time (min)

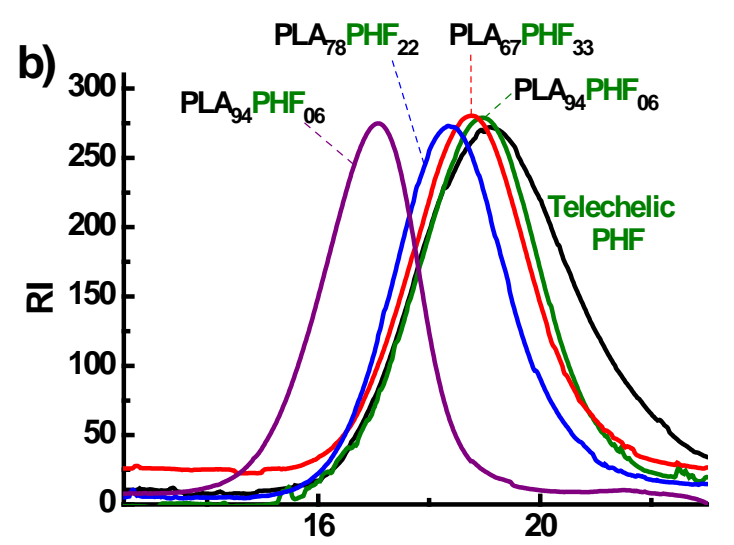

Retention Time (min)

Figure 4. GPC chromatograms of a) PHT and PLA- $b$-PHT- $b$-PLA copolyesters and $b$ ) PHF and PLA$b$-PHF- $b$-PLA copolyesters.

GPC chromatograms for both series are compared in Figure 4. For both PHT and PHF telechelic macro-initiators, broad bands with dispersities $(\theta)$ of 2.2 are observed at high elution volume. On the other hand, it is clearly observed that these bands are displaced at lower retention times by copolymerization, and this displacement is more evident as the content in lactic acid units increases in the copolymers. Monomodal bands with lower values of $€$ were observed for both series, indicating that $L$-lactide monomer is exclusively initiated by both PHT and PHF telechelic oligomers. Number and 
weight-average molar masses and dispersities $(\Theta)$ obtained from these chromatograms are collected in Table 1.

\section{Thermal Characterization}

The obtained PLA- $b$-PHAr- $b$-PLA triblock copolymers were thermally characterized. The thermal stability of materials made with PLA and PHT, as well as the materials made with PLA and PHF, showed similar trends. In both cases, it is observed that when the amount of PLA in the copolymers is increased, the thermal stability decreases (Figures S3 and S4, Supporting Information). However, when the amount of PLA present in the copolymer is $94 \%$, the thermal stability seems to increase and closely resembles that of pure PLA. ${ }^{30}$ It seems that a different mechanism of thermal degradation takes place for these high molecular weight copolyesters. In addition, the weight percentage shown in Table 1 for each copolymer can be corroborated by TGA, where the remaining weight percentage of PHT or PHF in the second stage of degradation corresponds to the weight percentage of the component in the copolymer.

Table 2 Thermal properties of triblock copolymers.

\begin{tabular}{|c|c|c|c|c|c|c|c|c|}
\hline \multirow{3}{*}{ Sample } & \multicolumn{8}{|c|}{ DSC } \\
\hline & \multirow[b]{2}{*}{$\begin{array}{c}T_{g} \\
\left({ }^{\circ} \mathrm{C}\right)\end{array}$} & \multicolumn{2}{|c|}{ Cooling } & \multicolumn{5}{|c|}{ Second heating } \\
\hline & & $\begin{array}{c}T_{c} \\
\left({ }^{\circ} \mathrm{C}\right)\end{array}$ & $\begin{array}{l}\Delta H_{c} \\
(\mathrm{~J} / \mathrm{g})\end{array}$ & $\begin{array}{c}T_{c c} \\
\left({ }^{\circ} \mathrm{C}\right)\end{array}$ & $\begin{array}{l}\Delta H_{c c} \\
(\mathrm{~J} / \mathrm{g})\end{array}$ & $\begin{array}{c}T_{m} \\
\left({ }^{\circ} \mathrm{C}\right)\end{array}$ & $\begin{array}{l}\Delta H_{m} \\
(\mathrm{~J} / \mathrm{g})\end{array}$ & $\begin{array}{c}\Delta H_{m F}{ }^{a} \\
(\mathrm{~J} / \mathrm{g})\end{array}$ \\
\hline Telechelic PHT & -8 & 105.3 & -46 & - & - & 139.2 & 46 & 46 \\
\hline $\mathrm{PLA}_{51} \mathrm{PHT}_{49}$ & 16 & 104.4 & -48 & - & - & 138.9 & 49 & 49 \\
\hline $\mathrm{PLA}_{66} \mathrm{PHT}_{34}$ & 35 & 102.4 & -47 & - & - & 139.8 & 44 & 44 \\
\hline $\mathrm{PLA}_{80} \mathrm{PHT}_{20}$ & 32 & 93.0 & -50 & - & - & 139.7 & 48 & 48 \\
\hline $\mathrm{PLA}_{94} \mathrm{PHT}_{06}$ & 43 & 53.4 & -11 & 64.5 & -13 & 134.6 & 33 & 20 \\
\hline Telechelic PHF & -5 & 91.8 & -57 & 122.5 & -1 & 141.3 & 59 & 58 \\
\hline $\mathrm{PLA}_{57} \mathrm{PHF}_{43}$ & 13 & 83.8 & -62 & - & - & 138.9 & 62 & 62 \\
\hline $\mathrm{PLA}_{67} \mathrm{PHF}_{33}$ & 18 & 76.0 & -13 & 79.3 & -40 & 135.8 & 60 & 20 \\
\hline $\mathrm{PLA}_{78} \mathrm{PHF}_{22}$ & 18 & 73.6 & -10 & 86.3 & -46 & 136.7 & 52 & 6 \\
\hline $\mathrm{PLA}_{94} \mathrm{PHF}_{06}$ & 45 & - & - & 114.5 & -8 & 138.1 & 12 & 4 \\
\hline
\end{tabular}

${ }^{a} \Delta H_{m F}$ represents the value the subtraction of $\left(\Delta H_{m}-\Delta H_{c c}\right)$.

The above is not true for the copolymer with a high PLA content, this may be due to the fact that the large amount of PLA in the copolymer generates a behavior similar 
to neat PLA, making the effect of the PHT or PHF existing in the copolymer insignificant, where the amount of the telechelic is very small compared to the amount of PLA present in the copolymer.

The thermal properties of the PLA-b-PHAr-b-PLA triblock copolymers $\left(T_{g}, T_{m}, T_{c}\right.$, $T_{c c}$ and $\Delta H$ ) were measured using differential scanning calorimetry (DSC). The values of these parameters are shown in Table 2. In this table, $\Delta H_{c}, \Delta H_{m}$, and $\Delta H_{c c}$ are normalized values (i.e., $\Delta H=\frac{\Delta H}{W}$, where $W$ is the mass fraction of the phase that crystallizes).

DSC second heating scans are shown in Figure 5 for the PLA- $b$-PHT- $b$-PLA triblock copolymers. In these triblock copolymers, it was found that the PLA blocks were not able to crystallize (this was corroborated by WAXS and will be shown below). The glass transition temperature is observed at around $30^{\circ} \mathrm{C}$, followed by melting at much higher temperatures (around $140{ }^{\circ} \mathrm{C}$ ). The melting transition occurs when PHT crystals melt. On the other hand, the presence of a single $T_{g}$ suggests that the PLA and PHT components are miscible in the amorphous state.

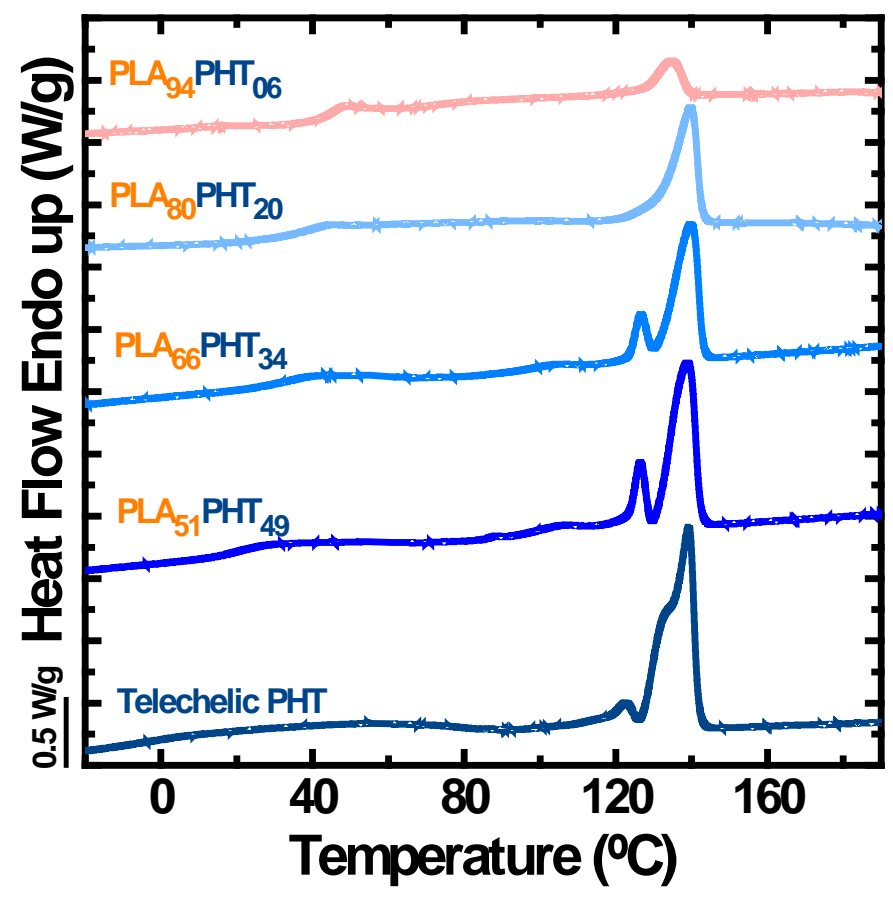

Figure 5. DSC second heating scans $\left(20^{\circ} \mathrm{C} / \mathrm{min}\right)$ for PHT and PLA- $b$-PHT- $b$-PLA triblock copolymers. 
Two melting peaks, or a bimodal melting peak, are observed in neat PHT and in two of the copolymers. These double melting peaks can be assigned to the melting of two different PHT polymorphs or recrystallization and melting during the scan. According to literature, it has been reported that PHT exhibits more than one melting peak. This is because this polymer crystallizes in three crystalline forms: $\alpha, \beta$ and $\gamma$, where depending on the thermal conditions to which the polymer has been exposed before measurement the formation of different polymorphs can be expected. ${ }^{22,31-35}$

It has been reported that when $\mathrm{PHT}$ is annealed at temperatures close to $140{ }^{\circ} \mathrm{C}$ or higher, the beta form tends to be more stable. On the other hand, when PHT is annealed at low or moderate temperatures $\left(<140{ }^{\circ} \mathrm{C}\right)$, there is a mixture of crystals of alpha and beta forms. There is a third crystalline form $(\gamma)$, which is usually found in solvent-induced crystallization at room temperature. ${ }^{22,32,35}$ The presence of different polymorphs as a function of temperature will be analysed below when the WAXS data is presented.
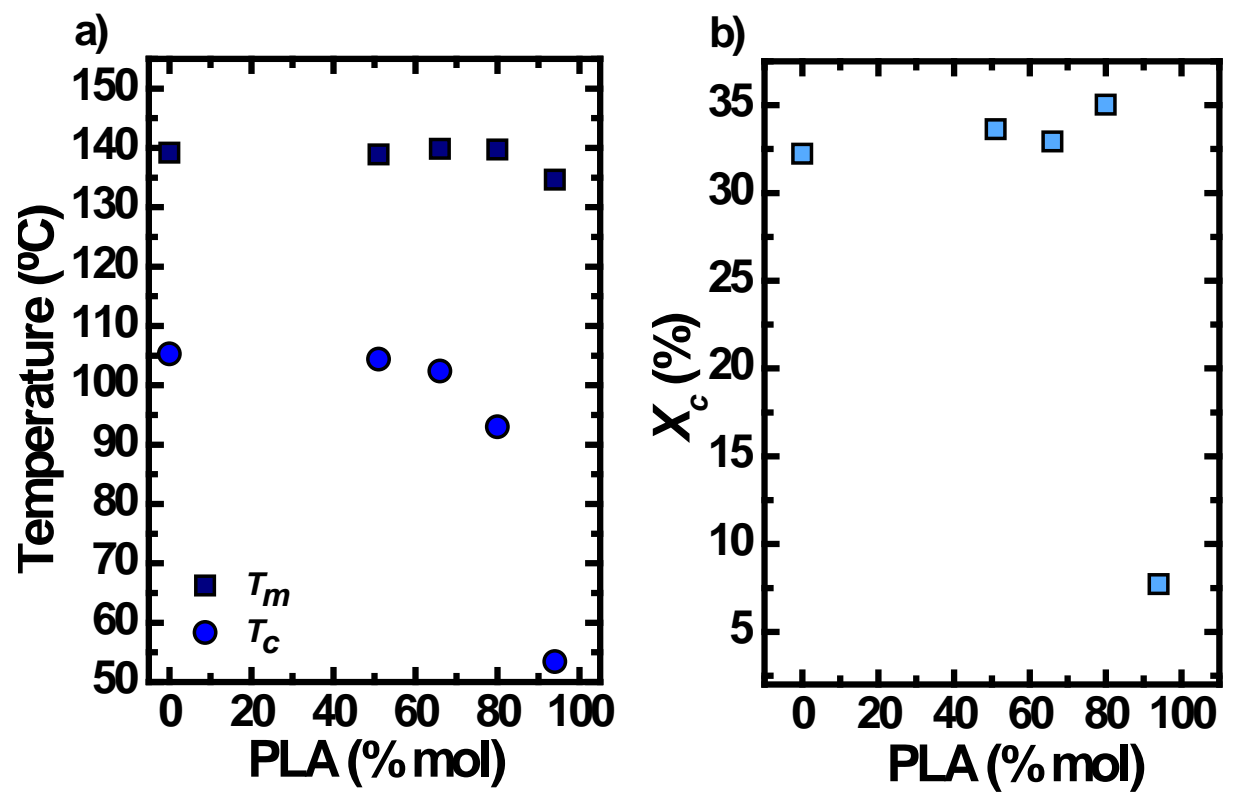

Figure 6. For PLA- $b$-PHT- $b$-PLA triblock copolymers: (a) Values of $T_{m}$ and $T_{c}$ as a function of composition and (b) $X_{c}$ versus composition. 
In the case of copolymers with 80 and 94 mol \% of PLA, only one melting peak is observed, this could be related to the high amount of PLA in the copolymer (Figure 5). The thermal properties $\left(T_{m}\right.$ and $\left.T_{c}\right)$ of the PHT versus the copolymers formed are similar to each other, indicating that the PLA does not affect significantly the crystallization behavior, only when there is $94 \%$ of PLA, a decrease in the $T_{c}$ of the material is noted (Figure 6). On the other hand, the crystallinity of the PHT block does not vary with composition except when 94\% PLA is present in the copolymer (Figure 6(b)). The percentage crystallinity $\left(X_{c}\right)$ was calculated by dividing $\Delta H_{c}$ (obtained from the cooling run) by $\Delta H_{m}^{o}$ (142.7 J/g for PHT) and then multiplying by $100 \% .{ }^{36}$ During cooling, all polymers exhibited a single crystallization peak (Figure S5, SI).

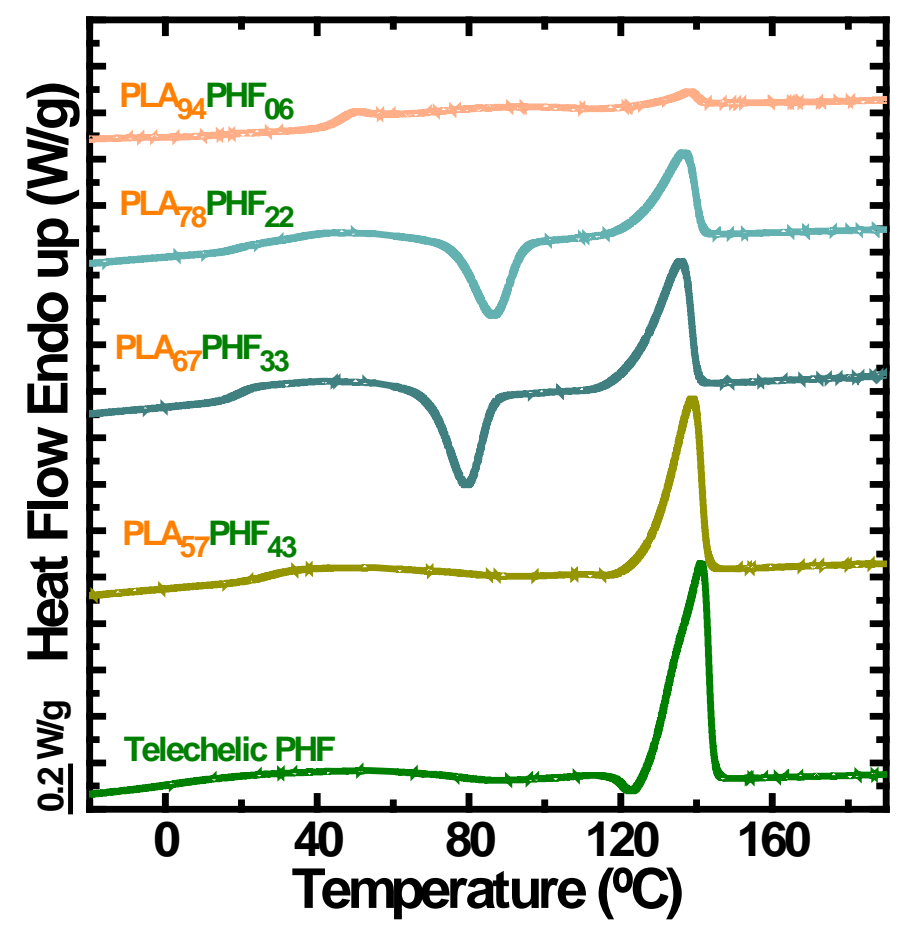

Figure 7. DSC second heating scans $\left(20^{\circ} \mathrm{C} / \mathrm{min}\right)$ for PHF and PLA- $b$-PHF- $b$-PLA triblock copolymers.

The series of copolymers made from PLA and PHF was also thermally characterized. Figure 7 shows the thermal behavior of neat PHF and the PLA- $b-\mathrm{PHF}-b$ PLA triblock copolymers. All materials exhibit melting endotherms. Above $57 \mathrm{~mol} \%$ of PLA, a pronounced cold crystallization exotherm is observed in the copolymers, 
indicating that the sample is not able to fully crystallize during the previous cooling run. Cold-crystallization processes (with rather low associated enthalpies) are also observed in the DSC heating scan of neat PHF at approximately $80^{\circ} \mathrm{C}$ and just before melting at $120^{\circ} \mathrm{C}$

In this series of copolymers the thermal properties $\left(T_{m}\right.$ and $\left.T_{c}\right)$, as well as the crystallinity $\left(X_{c}\right)$, are affected by the presence of PLA (Figure 8), where the trend suggests a decrease of these parameters when the amount of PLA in the copolymer increases, except for $T_{m}$ values. This can be explained by the cold-crystallization and reorganization processes that occur during the heating scans. To calculate $\left(X_{c}\right)$ a value of $\Delta H_{m}^{o}(143 \mathrm{~J} / \mathrm{g})$ corresponding to a PHF $100 \%$ crystalline was taken from the literature. ${ }^{24}$ During cooling from the melt, neat PHF and the PHF block within the copolymers exhibited a single crystallization peak (Figure S6, SI) that appears at lower temperature with the increased amount of PLA in the copolymer.
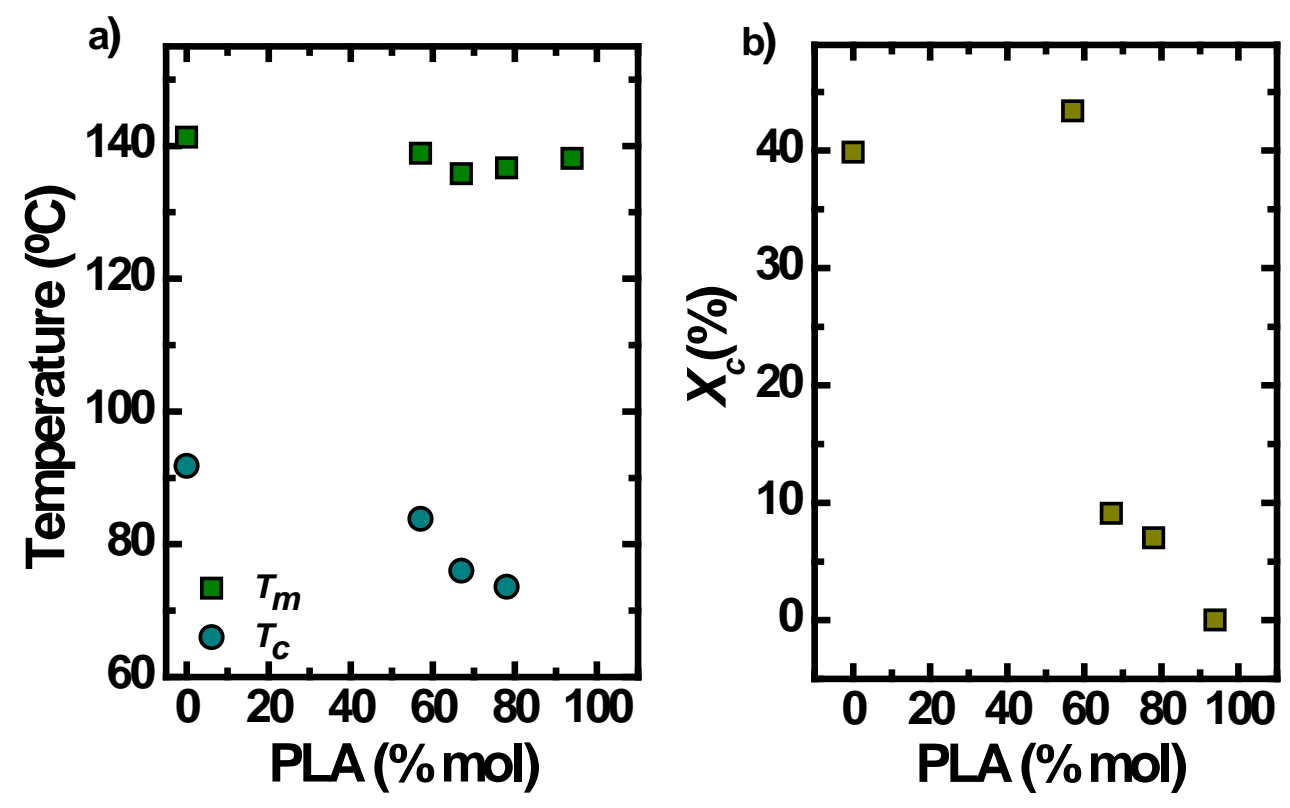

Figure 8. Thermal transitions for PLA- $b$-PHF- $b$-PLA triblock copolymers: (a) Values of $T_{m}$ and $T_{c}$ as a function of composition and (b) $X_{c}$ versus composition. 
PLA- $b$-PHT- $b$-PLA Triblock Copolymers

The structural characterization was performed by WAXS for both polymer series. For the copolymers derived from PHT and PLA, it was observed that only PHT crystals were formed, as their different crystalline forms are detected in the diffractogram (Figure 9). 22,31,32 In addition, the crystalline parameters characteristic of this homopolymer are shown in Table 3, and they all match with those reported in the literature. ${ }^{32,33}$

Table 3 Crystal cell parameters and crystal forms of PHT

\begin{tabular}{cccc}
\hline Crystal form designations & $\boldsymbol{\alpha}$ & $\boldsymbol{\beta}$ & $\boldsymbol{\gamma}$ \\
\hline Crystal geometry & monoclinic & triclinic & triclinic \\
\hline $\mathrm{a}(\mathrm{nm})$ & 0.91 & 0.48 & 0.53 \\
\hline $\mathrm{b}(\mathrm{nm})$ & 1.72 & 0.57 & 1.39 \\
\hline $\mathrm{c}(\mathrm{nm})$ & 1.55 & 1.57 & 1.55 \\
\hline
\end{tabular}

Figure 9 shows that depending on the temperature a specific PHT polymorph (alpha, beta or gamma) predominates in the structure, which is coherent with what is described in several works. $22,32,33$

A comparison has been made in Figure 9a vs. Figure $9 b$ between the temperature dependence of the crystalline structure of neat PHT and the PHT block within PLA ${ }_{51} \mathrm{PHT}_{49}$ copolymer respectively. The presence of the PLA blocks affects the crystallization of PHT block. For example, at $24{ }^{\circ} \mathrm{C}$, the crystalline forms exhibited by neat PHT are different from that shown by the copolymer (Figure 9b), but it is also observed that the number of crystalline forms found in the PHT tend to decrease in the copolymer. 
Table 4 Values of $q, 2 \vartheta$, crystalline planes and $d_{h k l}$ for neat PHT

\begin{tabular}{ccccc}
\hline Crystal form designations & $\boldsymbol{q} \mathbf{( n m}^{-1} \mathbf{)}$ & $\mathbf{2 \vartheta}$ & Planes & $\boldsymbol{d}_{\boldsymbol{h k l}}(\mathbf{n m})$ \\
\hline $\boldsymbol{\beta}_{\mathbf{1}}$ & 5.11 & 4.80 & --- & 1.23 \\
\hline $\boldsymbol{\gamma}_{\mathbf{2}}$ & 8.56 & 8.05 & --- & 0.734 \\
\hline $\boldsymbol{\beta}_{\mathbf{3}}$ & 11.66 & 10.97 & --- & 0.539 \\
\hline $\boldsymbol{\gamma}_{\mathbf{4}}$ & 12.25 & 11.53 & 100 & 0.513 \\
\hline $\boldsymbol{\beta}_{\mathbf{5}}$ & 13.08 & 12.31 & 100 & 0.480 \\
\hline $\boldsymbol{\alpha}_{\mathbf{6}}$ & 14.08 & 13.25 & 200 & 0.446 \\
\hline $\boldsymbol{\beta}_{\mathbf{7}}$ & 14.65 & 13.79 & 101 & 0.429 \\
\hline $\boldsymbol{\alpha}_{\mathbf{8}}$ & 15.11 & 14.23 & 130 & 0.416 \\
\hline $\boldsymbol{\beta}_{\mathbf{9}}$ & 15.60 & 14.69 & --- & 0.403 \\
\hline $\boldsymbol{\beta}_{\mathbf{1 0}}$ & 16.40 & 15.45 & 110 & 0.383 \\
\hline $\boldsymbol{\gamma}_{\mathbf{1 1}}$ & 17.10 & 16.11 & 120 & 0.367 \\
\hline $\boldsymbol{\alpha}_{\mathbf{1 2}}$ & 18.46 & 17.41 & 131 & 0.340 \\
\hline & & & &
\end{tabular}

Table 4 shows the values obtained from $2 \vartheta$, crystalline planes and the diffraction spaces ( $d_{h k l}$, calculated according to Bragg's Law) for the PHT. These values are in accordance with those reported by different authors. ${ }^{22,31-33,37,38}$
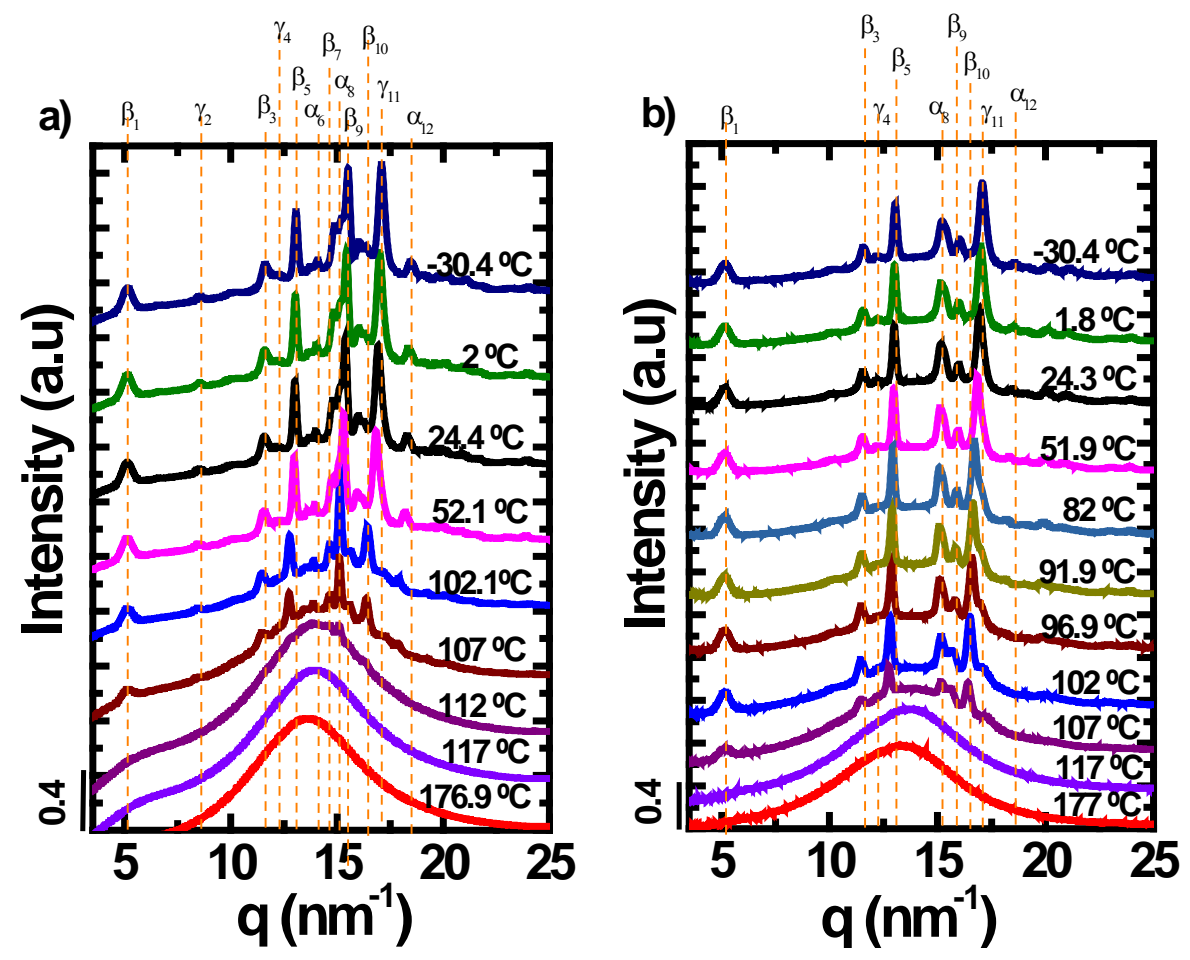

Figure 9. Real time synchrotron WAXS diffraction patterns for samples (a) PHT and (b) $\mathrm{PLA}_{51} \mathrm{PHT}_{49}$, cooled from $180{ }^{\circ} \mathrm{C}$ to $-30{ }^{\circ} \mathrm{C}$ at $20{ }^{\circ} \mathrm{C} / \mathrm{min}$. 
The WAXS results of the whole series of copolymers indicate that when the amount of PLA in the copolymers increases, the intensity of the crystalline peaks decreases, while the temperature at which the materials start to crystallize from the melt also decreases. In the case of the copolymer with 94 mol \% of PLA, no crystallization peak was exhibited in the diffractogram $(\mathrm{S9}, \mathrm{SI})$. The diffractograms of the rest of copolymers are shown in the Supporting Information.

The segregation strength between PHT and PLA was calculated $(\chi N)$. First, the Flory-Huggins interaction parameter $(\chi)$ between PHT and PLA was determined $(\chi=0.43)$ by Equations S1 and S2 in the Supporting Information.

The value of $N$ (total degree of polymerization) was calculated by equation 1 :

$$
N=\frac{\left(M n_{A} * \Phi_{A}\right)+\left(M n_{B} * \Phi_{B}\right)}{\left(M n r_{A} * \Phi_{A}\right)+\left(M n r_{B} * \Phi_{B}\right)}
$$

where $M n_{A}$ is the molecular weight of the PHT block (calculated by $M_{n}=L_{\mathrm{PHT}}$ from Table $1 * 248 \mathrm{~g} / \mathrm{mol}$ ), $M n_{B}$ is the molecular weight of the PLA block (calculated by $M_{n}=$ $L_{\text {PLA }}$ from Table $1 * 72 \mathrm{~g} / \mathrm{mol}$ ), $\Phi_{A}$ and $\Phi_{B}$ are the molar fractions of PHT and PLA (this molar fraction is calculated considering the block of PHT bound to only one block of PLA, that is, an $\mathrm{AB}$ link) respectively, present in the copolymer. $M n r_{A}$ is the molecular weight of the repeat unit of PHT $(248 \mathrm{~g} / \mathrm{mol})$ and $M n r_{B}$ is the molecular weight of the repeat unit of PLA (72 g/mol). The values of $N$ were calculated for every copolymer and the results are shown in Table 5.

Table 5 Values of $N$ and $\chi N$ for PLA- $b$-PHT- $b$-PLA triblock copolymers

\begin{tabular}{rcc}
\hline Sample & $\boldsymbol{N}$ & $\boldsymbol{\chi N}$ \\
\hline $\mathrm{PLA}_{51} \mathrm{PHT}_{49}$ & 13 & 6 \\
$\mathrm{PLA}_{66} \mathrm{PHT}_{34}$ & 14 & 6 \\
$\mathrm{PLA}_{80} \mathrm{PHT}_{20}$ & 19 & 8 \\
$\mathrm{PLA}_{94} \mathrm{PHT}_{06}$ & 81 & 35 \\
\hline
\end{tabular}

The segregation strength $(\chi N)$ values obtained are shown in Table 5. In a diblock copolymer, $(\chi N)$ is the parameter that controls the segregation between blocks $A$ and $B$. Usually the segregation is classified into three regimes: weak, intermediate and strong. Matsen and Bates, indicate that $\chi N \leq 10$ represents a copolymer without phase 
segregation, when $\chi N \approx 12$ indicates the beginning of a weak to intermediate segregation and a value of $\chi N \approx 50$ indicates the beginning of a segregation from intermediate to strong. ${ }^{39,40}$

In this case, the copolymers are triblock of the ABA form; therefore the parameter $\chi N$ is calculated for the interaction between one A block and one B block, that is, one side $A B$, considering that the other side $B A$ has the same interaction $\chi N$. In all copolymers, the $\chi N$ values are below 50 which indicate a weak to intermediate segregation strength in these systems. For copolymers with less than or equal to $80 \%$ PLA, the value of $\chi N$ is less than 10 , suggesting no segregation in these copolymers. On the other hand, a value of 35 for $\chi N$ is obtained when the copolymer has $94 \%$ PLA, which indicates that in this composition, segregation between the components of the copolymer (PHT and PLA) is more likely to occur. SAXS results (shown below) corroborate the trends indicated by the calculated segregation strengths.

To study the effect that the PLA has on the lamellar periodicity (average separation between stacked lamellar crystals), as well as on the lamellar thickness of the copolymers, SAXS experiments were carried out for copolymers derived from PHT and PLA. Figure 10 shows the SAXS results at different temperatures for (a) PHT and (b) $\mathrm{PLA}_{51} \mathrm{PHT}_{49}$ samples, where the Lorentz corrected intensity is plotted as a function of the scattering vector $q$. 

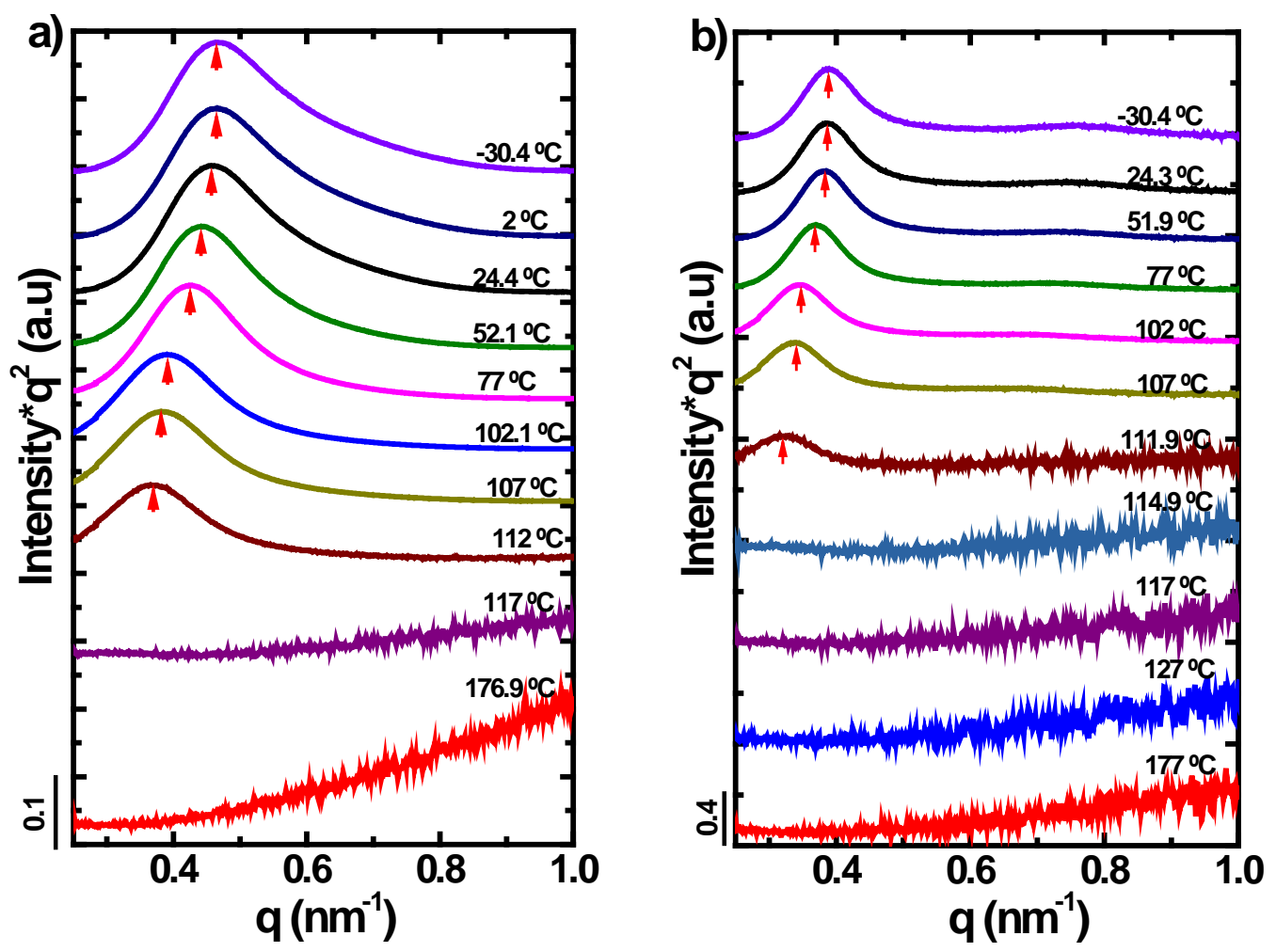

Figure 10. Lorentz-corrected SAXS profiles for (a) PHT and (b) $\mathrm{PLA}_{51} \mathrm{PHT}_{49}$, with intensity as a function of scattering vector. Data were taken in situ for samples cooled from $180{ }^{\circ} \mathrm{C}$ to $-30{ }^{\circ} \mathrm{C}$ at $20^{\circ} \mathrm{C} / \mathrm{min}$.

The materials exhibited a clear intense maximum due to the scattering caused by the periodic lamellar stacks (i.e., average separation between stacked lamellar crystals). The intensity of this maximum decreased as the amount of PLA increased in the copolymers. In the melt state, except for the copolymer with 94\% PLA, all copolymers did not exhibit any signal that could be attributed to the melt structure, indicating that there is no phase segregation and a single phase in the melt (see also the Supporting Information for SAXS data on the rest of the copolymers).

In the case of the copolymer with $94 \%$ of PLA, a signal in the melt state is detected, which suggests the existence of phase segregation in the copolymer (Figure S16, SI). This result is in line with the highest segregation strength reported in Table 5, as commented above. 
For every sample, the average separation between stacked lamellar crystals at different temperatures was estimated by eq. (2) from the respective $q_{\max }$ value obtained from the Lorentz corrected plots (Intensity* $q^{2}$ versus $q$ ).

$$
d^{*}=\frac{2 \pi}{q_{\max }}
$$

Figure 11 shows that the value of $d^{*}$ at low temperatures is a function of composition, the average separation between stacked lamellar crystals also increased with temperature, as the amorphous content increases, especially above $80{ }^{\circ} \mathrm{C}$, where melting can start in some of the samples.

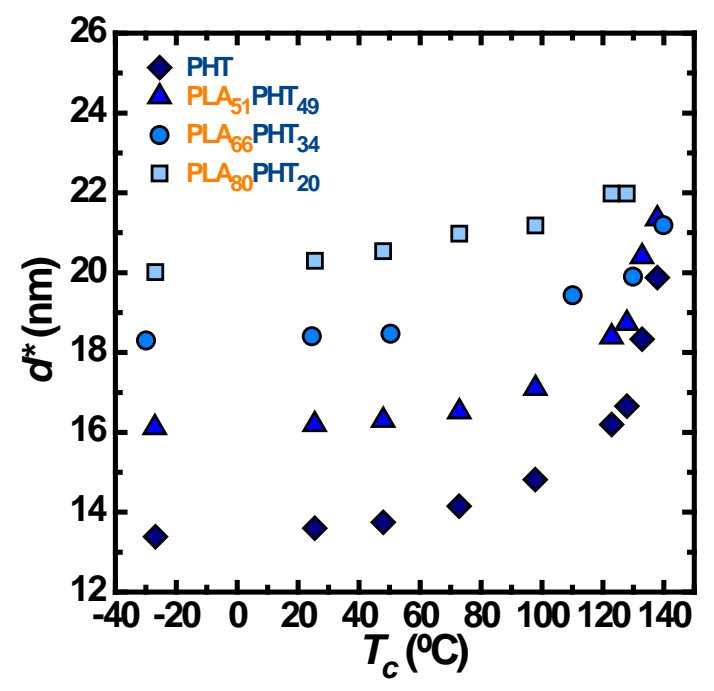

Figure 11. $d^{*}$ calculated from SAXS data as a function of temperature for PLA- $b$-PHT- $b$-PLA triblock copolymers.

Parameters such as the degree of crystallinity of each phase and the lamellar thickness (I), can be calculated from the analysis of data obtained from WAXS, SAXS and DSC. For the calculation of an average lamellar thickness ( $/$ ) the following approximation was employed:

$$
l=d^{*} \cdot X_{c}
$$


Table $6 d^{*}$, crystalline fraction $\left(X_{c}\right)$ and lamellar thickness (I) for PLA- $b$-PHT- $b$-PLA triblock copolymers

\begin{tabular}{|c|c|c|c|c|c|c|c|c|}
\hline Sample & $d^{*}(n m)$ & $\begin{array}{c}X c \\
\text { WAXS } \\
\end{array}$ & $\begin{array}{c}X C \\
\text { DSC }\end{array}$ & $\begin{array}{l}I(n m) \\
\text { WAXS }\end{array}$ & $\begin{array}{l}I(n m) \\
\text { DSC }\end{array}$ & $L(n m)$ & $\begin{array}{c}N F \\
W A X S\end{array}$ & $\begin{array}{l}N F \\
D S C\end{array}$ \\
\hline PHT & 13.5 & 0.18 & 0.32 & 2.5 & 4.4 & 22 & 9.0 & 5.1 \\
\hline $\mathrm{PLA}_{51} \mathrm{PHT}_{49}$ & 16.2 & 0.20 & 0.34 & 3.2 & 5.5 & 22 & 6.8 & 4.0 \\
\hline $\mathrm{PLA}_{66} \mathrm{PHT}_{34}$ & 18.4 & 0.27 & 0.33 & 5.0 & 6.1 & 22 & 4.4 & 3.6 \\
\hline $\mathrm{PLA}_{80} \mathrm{PHT}_{20}$ & 20.3 & --- & 0.35 & --- & 7.1 & 22 & --- & 3.1 \\
\hline $\mathrm{PLA}_{94} \mathrm{PHT}_{06}$ & --- & --- & 0.08 & --- & --- & --- & --- & --- \\
\hline
\end{tabular}

Table 6 shows the values of $X_{c}$ determined by DSC. Using these values the lamellar thickness (/) was calculated (Table 6). As the lamellar thickness values depend on the crystallinity degree, according to equation 3 , the degree of crystallinity was estimated by both DSC and WAXS. An example of crystallinity determination by WAXS is provided in Figure S10, SI. Table 6 lists the lamellar thickness calculated with crystallinity values derived from both DSC and WAXS.

The WAXS results indicate that the PLA does not crystallize, and that the only block capable of crystallizing is the PHT, corroborating what is shown in the DSC scans, where only peaks corresponding to PHT were detected (Figure 5). The degree of crystallinity $\left(X_{c}\right)$ in the copolymers does not seem to vary much when the amount of PLA is increased. This behavior is observed below $80 \%$ PLA, above this composition (94\% PLA), the degree of crystallinity decreases remarkably (Table 6 and Figure 6b).

The SAXS technique reflects only the diffraction caused by the PHT lamellae. As the PLA content increases in the copolymer, the PHT lamellar crystals are more separated from each other and therefore the value of $d^{*}$ increases.

Table 6 shows that the value of / tends to increase, as the PLA content increases in the copolymers. It should be noted that the molecular weight of the PHT block is the same for all copolymers. Hence, it is expected that the lamellar thickness should not vary significantly. Nevertheless, even considering the experimental errors involved in 
crystallinity determination by both DSC and WAXS, and in the SAXS experiments, which are of the order of $10-15 \%$, an increasing trend in / values is observed in Table 6 beyond that error. However, increases of the order of 1 to $2 \mathrm{~nm}$ are not significant enough to influence $T_{m}$ values (see Figure 6 above). Therefore, the SAXS results are consistent with the DSC results presented above.

PLA- $b$-PHF- $b$-PLA Triblock Copolymers

The crystal lattice of PHF is a triclinic $\beta$-form (unit cell values of PHF are not reported in the literature), and its crystalline reflections are reported in Table 7 and are consistent with the literature. ${ }^{25}$

Table 7 Values of $q, 2 \vartheta$, crystalline planes and $d_{h k l}$ for PHF

\begin{tabular}{cccc}
\hline $\boldsymbol{q}\left(\mathbf{n m}^{-1}\right)$ & $\mathbf{2 \vartheta}$ & Planes & $\boldsymbol{d}_{\boldsymbol{h k l}}(\mathbf{n m})$ \\
\hline 9.77 & 9.19 & 002 & 0.643 \\
\hline 12.13 & 11.41 & 011 & 0.518 \\
\hline 17.69 & 16.67 & 100 & 0.355 \\
\hline
\end{tabular}

In Figure 12, the characteristic WAXS diffractograms of PHF (Figure 12a) and the $\mathrm{PLA}_{57} \mathrm{PHF}_{43}$ copolymer (Figure 12b) are shown as a function of temperature. It is observed that PLA causes an effect on the crystallization of PHF, for example at $25^{\circ} \mathrm{C}$ the intensity of the peaks decreases in the copolymer as compared to the homopolymer. On the other hand, the temperature at which the materials start to crystallize from the melt also decreases when PLA is present in the copolymer. In the case of the copolymer with 94 mol\% of PLA, no crystallization peak in the diffractogram was obtained (see Supporting Information). The diffractograms of the rest of copolymers are shown in the Supporting Information. 

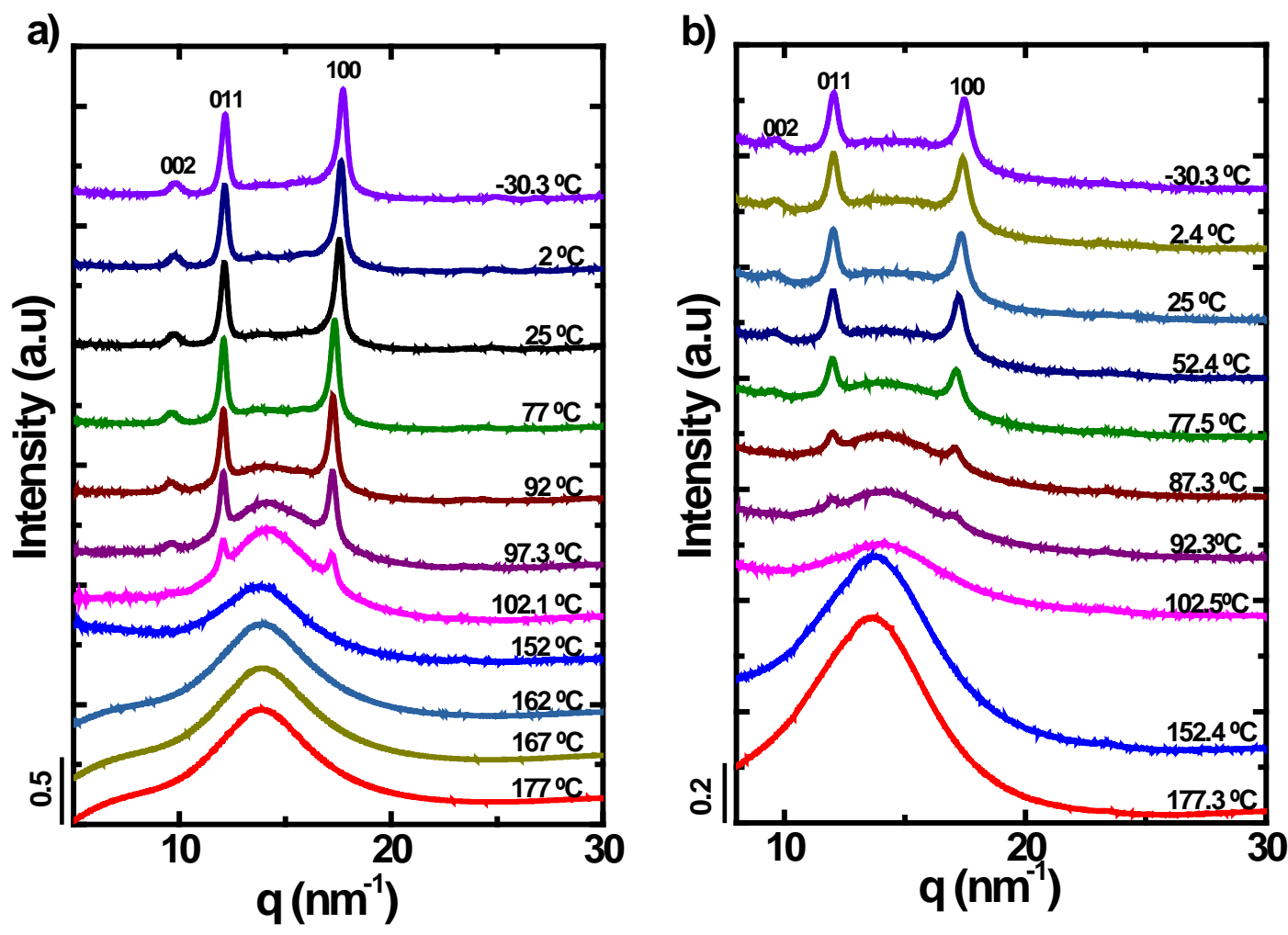

Figure 12. Real-time synchrotron WAXS diffraction patterns for samples (a) PHF and (b) $\mathrm{PLA}_{57} \mathrm{PHF}_{43}$, cooled from the $180^{\circ} \mathrm{C}$ to $-30{ }^{\circ} \mathrm{C}$ at $20^{\circ} \mathrm{C} / \mathrm{min}$.

The segregation strength between PHF and PLA was calculated $(\chi N)$, following the procedure described for the copolymers of PLA/PHT (see Supporting Information). The interaction parameter $\chi$ was calculated and value of $\chi=0.34$ was obtained. The value of $N$ (total degree of polymerization) was calculated by equation (1), where $M n_{A}$ is is the molecular weight of the PHF block (calculated by $M n=L_{P H F}$ from Table $1 * 238 \mathrm{~g} / \mathrm{mol}$ ) and $M n r_{A}$ is the molecular weight of the repeat unit of PHF $(238 \mathrm{~g} / \mathrm{mol})$. The values of $N$ were calculated for every copolymer and the results are shown in Table 8. 
Table $8 N$ and $\chi N$ for PLA- $b$-PHF- $b$-PLA triblock copolymers

\begin{tabular}{rcc}
\hline Sample & $\boldsymbol{N}$ & $\boldsymbol{\chi N}$ \\
\hline $\mathrm{PLA}_{57} \mathrm{PHF}_{43}$ & 15 & 5 \\
$\mathrm{PLA}_{67} \mathrm{PHF}_{33}$ & 16 & 5 \\
$\mathrm{PLA}_{78} \mathrm{PHF}_{22}$ & 22 & 7 \\
$\mathrm{PLA}_{94} \mathrm{PHF}_{06}$ & 87 & 30 \\
\hline
\end{tabular}

In all copolymers, the $\chi N$ values are below 50 which indicate a weak to intermediate segregation strength in these systems. For copolymers with less than or equal to $78 \%$ PLA, the value of $\chi N$ is less than 10 , suggesting that no phase segregation occurs in these copolymers. On the other hand, a value of 30 for $\chi N$ is obtained when the copolymer has a 94\% PLA. This indicates that for this composition an intermediate segregation strength is obtained. However, SAXS data revealed no segregation in the molten state, suggesting that the system tends more to weak segregation or no segregation. These results are shown below.
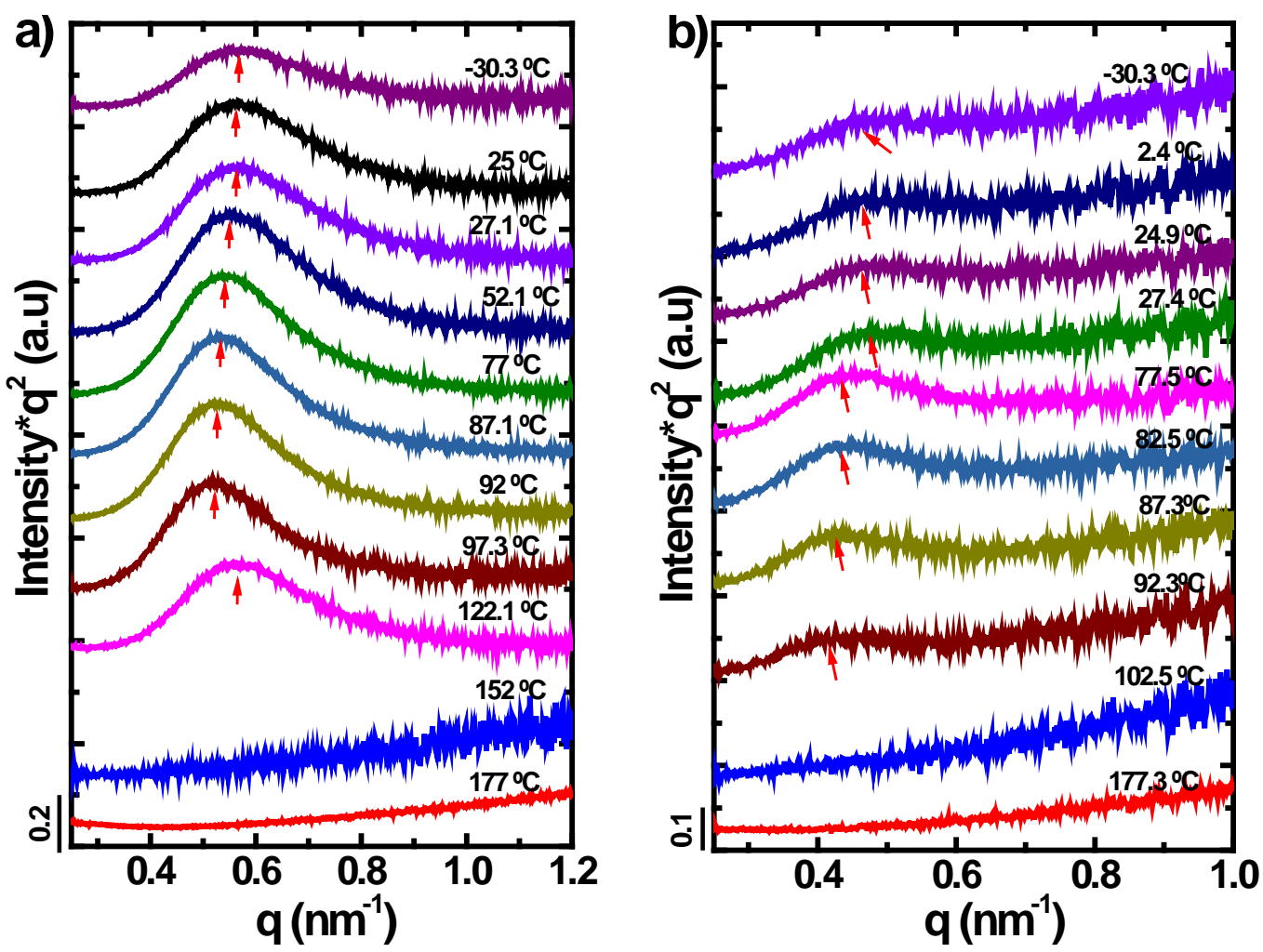

Figure 13. Lorentz-corrected SAXS profiles for (a) PHF and (b) $\mathrm{PLA}_{57} \mathrm{PHF}_{43}$, with intensity as a function of scattering vector. Data were taken in situ for samples cooled from $180{ }^{\circ} \mathrm{C}$ to $-30{ }^{\circ} \mathrm{C}$ at $20^{\circ} \mathrm{C} / \mathrm{min}$. 
For this series of copolymers made with PLA and PHF, SAXS experiments were also carried out, Figure 13 shows the SAXS results at different temperatures for (a) PHF and (b) $\mathrm{PLA}_{57} \mathrm{PHF}_{43}$ samples, where the intensity is plotted as a function of the scattering vector $q$. The copolymers showed a clear intense maximum due to the scattering caused by the periodic lamellar stacks (i.e., average separation between stacked lamellar crystals) of PHF. The intensity of this maximum decreased as the amount of PLA increased in the copolymers. In the melt state, no SAXS scattering was observed, indicating a single-phase melt structure (Supporting Information).

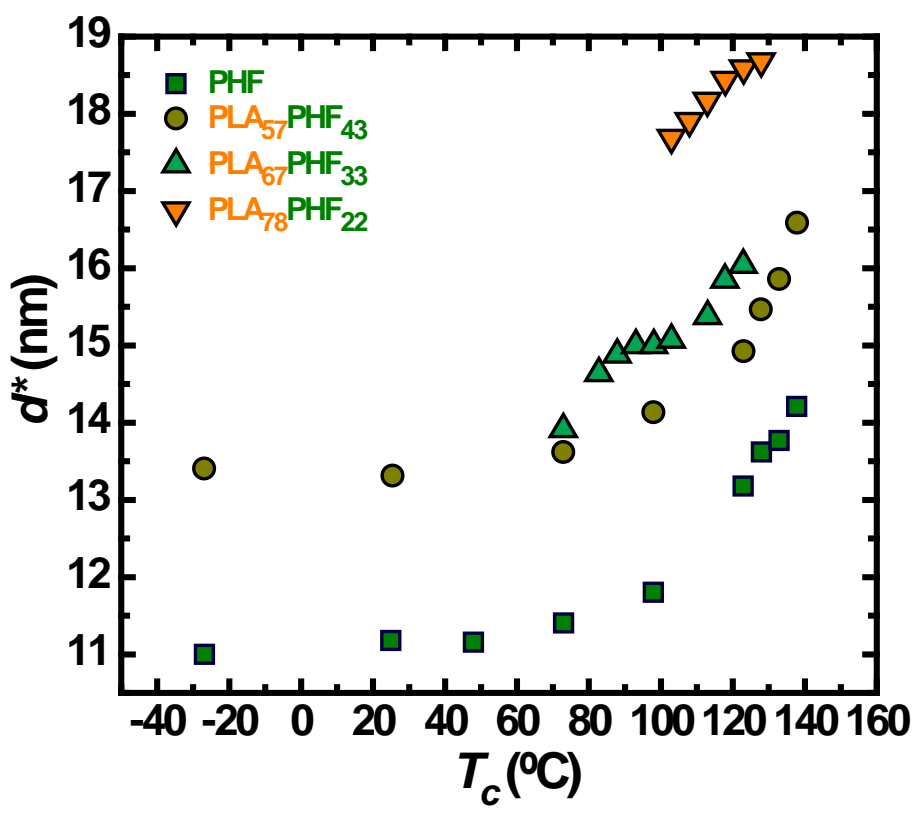

Figure 14. $d^{*}$ calculated from SAXS data as a function of temperature for PLA- $b$-PHF- $b$-PLA triblock copolymers.

The average separation between stacked lamellar crystals at different temperatures for each sample was estimated by eq. (2) from $q_{\max }$ values taken from the Lorentz corrected plots (Intensity* $q^{2}$ versus $q$ ). Figure 14 shows that the value of $d^{*}$ at low temperatures is a function of composition. The average separation between stacked lamellar crystals increased with temperature, especially at high temperatures where melting has started. With compositions above $67 \%$ of PLA, the intensities in SAXS at low temperatures were so small that it was not possible to measure and report these values. 
Table 9 shows the values of $X_{c}$ and lamellar thickness (I) were calculated (Table 9) by both DSC and WAXS.

Table $9 d^{*}$, crystalline fraction $\left(X_{c}\right)$ and lamellar thickness $(/)$ for PLA- $b$-PHF- $b$-PLA triblock copolymers

\begin{tabular}{cccccc} 
& & $X c$ & $X C$ & $I(n m)$ & $I(n m)$ \\
Sample & $d^{*}(n m)$ & WAXS & DSC & WAXS & DSC \\
\hline PHT & 11.2 & 0.35 & 0.40 & 3.9 & 4.5 \\
\hline $\mathrm{PLA}_{57} \mathrm{PHF}_{43}$ & 13.3 & 0.40 & 0.43 & 5.3 & 5.7 \\
\hline $\mathrm{PLA}_{67} \mathrm{PHF}_{33}$ & --- & 0.18 & 0.09 & --- & --- \\
\hline $\mathrm{PLA}_{78} \mathrm{PHF}_{22}$ & --- & 0.04 & 0.07 & --- & --- \\
\hline $\mathrm{PLA}_{94} \mathrm{PHF}_{06}$ & --- & --- & --- & --- & --- \\
\hline- - Values of $X c$ and $d^{*}$ calculated with data from WAXS and SAXS respectively at $25^{\circ} \mathrm{C}$.
\end{tabular}

Table 9 clearly shows how the crystallinity decreases with the PLA content in the sample when the amount of PLA is above $57 \%$ in the copolymer. The lamellar thickness value (I), seems to change only slightly in the composition with 57\% PLA versus the homopolymer, this is expected since the PHF block has the same molecular weight in all the copolymers. For the rest of the compositions, the signals of $d^{*}$ were not determined as their intensity was too low.

The results by WAXS and DSC confirm that the only block that crystallizes in the copolymers is the PHF. SAXS showed the diffraction corresponding to the crystalline phase (PHF), and it is expected that the average separation between stacked lamellar crystals increases with the PLA content.

The copolymers containing PHT exhibit thermal properties and crystallinities that decrease markedly above $80 \%$ of PLA, while the copolymers containing PHF begin to have changes in these properties at compositions with more than $57 \%$ of PLA. These results suggest that the copolymers with PHT are less affected by the presence of PLA than the copolymers with PHF. From the above, it can be concluded that by increasing the amount of PLA in the copolymers, its thermal properties and crystallinity tend to decrease (scheme 2). 


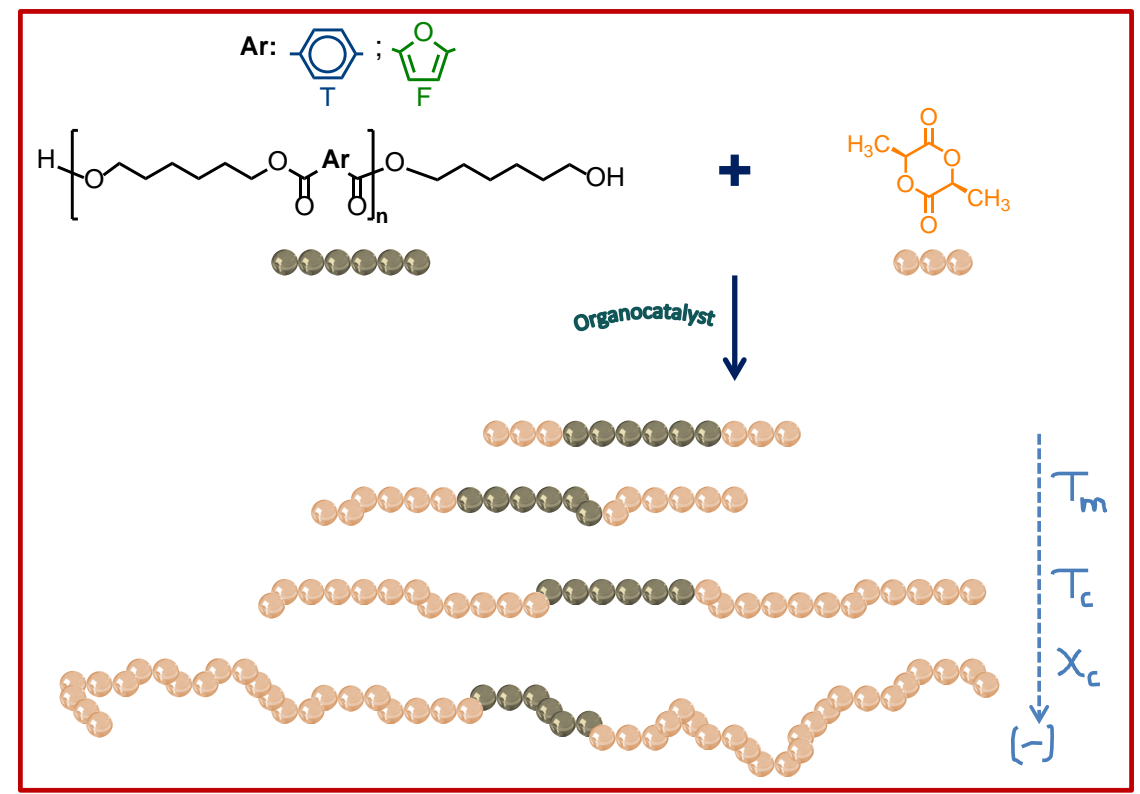

Scheme 2. Influence of composition on thermal properties and crystallinity

\section{Conclusions}

ABA triblock copolymers with A being PLA and B being either PHT or PHF were successfully prepared using organocatalysis. The triblock structure of the copolymers was demonstrated by NMR and the absence of transesterification was confirmed. Each synthesized copolymer has different PLA block length and identical PHT or PHF block lengths. In addition, both series of copolymers have in their structure blocks that may be susceptible to degradation (PLA), but also the polymer of the central block, PHT or PHF can be made from monomers derived from plastic waste or renewable sources, respectively. Therefore, these triblock copolymers follow the sustainability line in their synthesis route.

The behavior shown by the copolymers indicates that the PLA block is unable to crystallize in both series, i.e., in PLA- $b$-PHT- $b$-PLA or PLA- $b$-PHF- $b$-PLA triblock copolymers. PHT and PHF are the only crystalline phases within the triblock copolymers. The amount of PLA present in the copolymers does not significantly affect the thermal properties and crystallinity of the copolymers up to a critical amount, above which these properties decrease markedly. 
Even though the structural and thermal properties shown by both families of copolymers are linked to PLA, they behaved qualitatively similar. It is noteworthy that copolymers made with PHT tolerate a larger amount of PLA before showing significant changes in their properties, in comparison with the copolymers made with PHF.

\section{Acknowledgments}

The POLYMAT/UPV/EHU team would like to acknowledge funding from MINECO through project: MAT2017-83014-C2-1-P, and from ALBA synchrotron facility. We also acknowledge the financial contribution of the Basque Government through grant IT1309-19 and the funding of the European Union's Horizon 2020 research and innovation programme under the Marie Sklodowska-Curie grant agreement No 778092". Irma Flores would like to acknowledge CONACYT (Mexico) for the Ph.D. grant awarded.

\section{References}

(1) Nakajima, H.; Dijkstra, P.; Loos, K. The Recent Developments in Biobased Polymers toward General and Engineering Applications: Polymers That Are Upgraded from Biodegradable Polymers, Analogous to Petroleum-Derived Polymers, and Newly Developed. Polymers 2017, 9 (12), 523. https://doi.org/10.3390/polym9100523.

(2) Genovese, L.; Soccio, M.; Lotti, N.; Gazzano, M.; Siracusa, V.; Salatelli, E.; Balestra, F.; Munari, A. Design of Biobased PLLA Triblock Copolymers for Sustainable Food Packaging: Thermo-Mechanical Properties, Gas Barrier Ability and Compostability. Eur. Polym. J. 2017, 95, 289-303. https://doi.org/10.1016/j.eurpolymj.2017.08.001.

(3) Shi, S. X.; Xia, Y. Z.; Ma, X. Y.; Jiao, S. K.; Li, X. Y. Synthesis and Properties of Biodegradable ABA Triblock Copolymers of Polylactide (A) and Polyethylene Glycol (B). Adv. Mater. Res. 2006, 11-12, 469-472. https://doi.org/10.4028/www.scientific.net/AMR.11-12.469. 
(4) Xiao, L.; Wang, B.; Yang, G.; Gauthier, M. Poly(Lactic Acid)-Based Biomaterials: Synthesis, Modification and Applications. In Biomedical Science, Engineering and Technology; Ghista, D. N., Ed.; InTech, 2012. https://doi.org/10.5772/23927.

(5) van der Meulen, I.; Gubbels, E.; Huijser, S.; Sablong, R.; Koning, C. E.; Heise, A.; Duchateau, R. Catalytic Ring-Opening Polymerization of Renewable Macrolactones to High Molecular Weight Polyethylene-like Polymers. Macromolecules 2011, 44 (11), 4301-4305. https://doi.org/10.1021/ma200685u.

(6) Knani, D.; Gutman, A. L.; Kohn, D. H. Enzymatic Polyesterification in Organic Media. Enzyme-Catalyzed Synthesis of Linear Polyesters. I. Condensation Polymerization of Linear Hydroxyesters. II. Ring-Opening Polymerization of $\varepsilon$-Caprolactone. J. Polym. Sci. Part Polym. Chem. 1993, 31 (5), 1221-1232. https://doi.org/10.1002/pola.1993.080310518.

(7) van der Mee, L.; Helmich, F.; de Bruijn, R.; Vekemans, J. A. J. M.; Palmans, A. R. A.; Meijer, E. W. Investigation of Lipase-Catalyzed Ring-Opening Polymerizations of Lactones with Various Ring Sizes: Kinetic Evaluation. Macromolecules 2006, 39 (15), 5021-5027. https://doi.org/10.1021/ma060668j.

(8) Bouyahyi, M.; Duchateau, R. Metal-Based Catalysts for Controlled Ring-Opening Polymerization of Macrolactones: High Molecular Weight and Well-Defined Copolymer Architectures. Macromolecules 2014, 47 (2), 517-524. https://doi.org/10.1021/ma402072t.

(9) Hu, Y.; Daoud, W.; Cheuk, K.; Lin, C. Newly Developed Techniques on Polycondensation, Ring-Opening Polymerization and Polymer Modification: Focus on Poly(Lactic Acid). Materials 2016, $9 \quad$ (3), 133. https://doi.org/10.3390/ma9030133.

(10) González-Vidal, N.; Martínez de llarduya, A.; Muñoz-Guerra, S. Poly(Hexamethylene Terephthalate-Co-Caprolactone) Copolymers: Influence of Cycle Size on Ring-Opening Polymerization. Eur. Polym. J. 2010, 46 (4), 792-803. https://doi.org/10.1016/j.eurpolymj.2009.12.016.

(11) Ding, Y.; Lu, B.; Wang, P.; Wang, G.; Ji, J. PLA-PBAT-PLA Tri-Block Copolymers: Effective Compatibilizers for Promotion of the Mechanical and Rheological Properties of PLA/PBAT Blends. Polym. Degrad. Stab. 2018, 147, 41-48. https://doi.org/10.1016/j.polymdegradstab.2017.11.012. 
(12) Ding, Y.; Feng, W.; Lu, B.; Wang, P.; Wang, G.; Ji, J. PLA-PEG-PLA Tri-Block Copolymers: Effective Compatibilizers for Promotion of the Interfacial Structure and Mechanical Properties of PLA/PBAT Blends. Polymer 2018, 146, 179-187. https://doi.org/10.1016/j.polymer.2018.05.037.

(13) Sun, Z.; Zhang, B.; Bian, X.; Feng, L.; Zhang, H.; Duan, R.; Sun, J.; Pang, X.; Chen, W.; Chen, X. Synergistic Effect of PLA-PBAT-PLA Tri-Block Copolymers with Two Molecular Weights as Compatibilizers on the Mechanical and Rheological Properties of PLA/PBAT Blends. RSC Adv. 2015, 5 (90), 73842-73849. https://doi.org/10.1039/C5RA11019J.

(14) Zeng, J.-B.; Li, K.-A.; Du, A.-K. Compatibilization Strategies in Poly(Lactic Acid)-Based Blends. RSCAdv. 2015, 5 (41), 32546-32565. https://doi.org/10.1039/C5RA01655J.

(15) Wang, Y.; Hillmyer, M. A. Polyethylene-Poly(L-Lactide) Diblock Copolymers: Synthesis and Compatibilization of Poly(L-Lactide)/Polyethylene Blends. J. Polym. Sci. Part Polym. Chem. 2001, 39 (16), 2755-2766. https://doi.org/10.1002/pola.1254.

(16) Tsuji, H.; Yamada, T.; Suzuki, M.; Itsuno, S. Part 7. Effects of Poly(L-Lactide-Co- $\varepsilon-$ Caprolactone) on Morphology, Structure, Crystallization, and Physical Properties of Blends of Poly(L-Lactide) and Poly(ع-Caprolactone). Polym. Int. 2003, 52 (2), 269275. https://doi.org/10.1002/pi.1093.

(17) Chumeka, W.; Pasetto, P.; Pilard, J.-F.; Tanrattanakul, V. Bio-Based Diblock Copolymers Prepared from Poly(Lactic Acid) and Natural Rubber. J. Appl. Polym. Sci. 2015, 132 (6), n/a-n/a. https://doi.org/10.1002/app.41426.

(18) Maglio, G.; Malinconico, M.; Migliozzi, A.; Groeninckx, G. Immiscible Poly(LLactide)/Poly( $\varepsilon$-Caprolactone) Blends: Influence of the Addition of a Poly(LLactide)-Poly(Oxyethylene) Block Copolymer on Thermal Behavior and Morphology. Macromol. Chem. Phys. 2004, 205 (7), 946-950. https://doi.org/10.1002/macp.200300150.

(19) Robertson, M. L.; Chang, K.; Gramlich, W. M.; Hillmyer, M. A. Toughening of Polylactide with Polymerized Soybean Oil. Macromolecules 2010, 43 (4), 18071814. https://doi.org/10.1021/ma9022795.

(20) González-Vidal, N.; de Ilarduya, A. M.; Muñoz-Guerra, S.; Castell, P.; Martínez, M. T. Synthesis and Properties of Poly(Hexamethylene Terephthalate)/Multiwall 
Carbon Nanotubes Nanocomposites. Compos. Sci. Technol. 2010, 70 (5), 789-796. https://doi.org/10.1016/j.compscitech.2010.01.014.

(21) Flores, I.; Martínez de Ilarduya, A.; Sardon, H.; Müller, A. J.; Muñoz-Guerra, S. Synthesis of Aromatic-Aliphatic Polyesters by Enzymatic Ring Opening Polymerization of Cyclic Oligoesters and Their Cyclodepolymerization for a Circular Economy. ACS Appl. Polym. Mater. 2019, 1 (3), 321-325. https://doi.org/10.1021/acsapm.8b00265.

(22) Wu, M. C.; Woo, E. M.; Yoshioka, T.; Tsuji, M. Thermal Analysis, X-Ray and Electron Diffraction Studies on Crystalline Phase Transitions in Solvent-Treated Poly(Hexamethylene Terephthalate). Polymer 2006, 47 (15), 5523-5530. https://doi.org/10.1016/j.polymer.2005.05.161.

(23) Jiang, M.; Liu, Q.; Zhang, Q.; Ye, C.; Zhou, G. A Series of Furan-Aromatic Polyesters Synthesized via Direct Esterification Method Based on Renewable Resources. J. Polym. Sci. Part Polym. Chem. 2012, 50 (5), 1026-1036. https://doi.org/10.1002/pola.25859.

(24) Papageorgiou, G. Z.; Tsanaktsis, V.; Papageorgiou, D. G.; Chrissafis, K.; Exarhopoulos, S.; Bikiaris, D. N. Furan-Based Polyesters from Renewable Resources: Crystallization and Thermal Degradation Behavior of Poly(Hexamethylene 2,5-Furan-Dicarboxylate). Eur. Polym. J. 2015, 67, 383-396. https://doi.org/10.1016/j.eurpolymj.2014.08.031.

(25) Jiang, Y.; Woortman, A. J. J.; Alberda van Ekenstein, G. O. R.; Loos, K. A Biocatalityc Approach towards Sustainabe 2,5 Furandicarboxylic Acid Based Furanic-Aliphatic Polyesters. Polym 2015, 6, 5198-5211. https://doi.org/10.1039/C5PY00629E.

(26) Zakharova, E.; León, S.; de Ilarduya, A. M.; Muñoz-Guerra, S. Triblock Copolyesters Derived from Lactic Acid and Glucose: Synthesis, Nanoparticle Formation and Simulation. Eur. Polym. J. 2017, 92, 1-12. https://doi.org/10.1016/j.eurpolymj.2017.04.033.

(27) Zakharova, E.; Martínez de Ilarduya, A.; León, S.; Muñoz-Guerra, S. HydroxylFunctionalized Amphiphilic Triblock Copolyesters Made of Tartaric and Lactic Acids: Synthesis and Nanoparticle Formation. React. Funct. Polym. 2018, 126, 52-62. https://doi.org/10.1016/j.reactfunctpolym.2018.03.007. 
(28) de Ilarduya, A. M.; Muñoz-Guerra, S. Chemical Structure and Microstructure of Poly(Alkylene Terephthalate)s, Their Copolyesters, and Their Blends as Studied by NMR. Macromol. Chem. Phys. 2014, 215 (22), 2138-2160. https://doi.org/10.1002/macp.201400239.

(29) Pothupitiya, J. U.; Dharmaratne, N. U.; Jouaneh, T. M. M.; Fastnacht, K. V.; Coderre, D. N.; Kiesewetter, M. K. H-Bonding Organocatalysts for the Living, Solvent-Free Ring-Opening Polymerization of Lactones: Toward an All-Lactones, All-Conditions Approach. Macromolecules 2017, $50 \quad$ (22), 8948-8954. https://doi.org/10.1021/acs.macromol.7b01991.

(30) Liu, T.-Y.; Lin, W.-C.; Yang, M.-C.; Chen, S.-Y. Miscibility, Thermal Characterization and Crystallization of Poly(L-Lactide) and Poly(Tetramethylene Adipate-CoTerephthalate) Blend Membranes. Polymer 2005, 46 (26), 12586-12594. https://doi.org/10.1016/j.polymer.2005.10.100.

(31) Woo, E.; Wu, P.-L.; Chiang, C.-P.; Liu, H.-L. Analysis of Polymorphism and Dual Crystalline Morphologies in Poly(Hexamethylene Terephthalate). Macromol. Rapid Commun. 2004, 25 (9), 942-948. https://doi.org/10.1002/marc.200300307.

(32) Ghosh, A. K.; Woo, E. M.; Sun, Y.-S.; Lee, L.-T.; Wu, M.-C. Characterization and Analyses on Complex Melting, Polymorphism, and Crystal Phases in MeltCrystallized Poly(Hexamethylene Terephthalate). Macromolecules 2005, 38 (11), 4780-4790. https://doi.org/10.1021/ma0473667.

(33) Inomata, K.; Sasaki, S. Crystal Structure and Conformational Disorder of Poly(Hexamethylene Terephthalate). J. Polym. Sci. Part B Polym. Phys. 1996, 34 (1), 83-92. https://doi.org/10.1002/(SICI)1099-0488(19960115)34:1<83::AIDPOLB6>3.0.CO;2-X.

(34) Sun, Y.-S. Temperature-Resolved SAXS Studies of Morphological Changes in MeltCrystallized Poly(Hexamethylene Terephthalate) and Its Melting upon Heating. Polymer 2006, 47 (23), 8032-8043. https://doi.org/10.1016/j.polymer.2006.09.003.

(35) Hall, I. H.; Ibrahim, B. A. The Structure and Properties of Poly(Hexamethylene Terephthalate): 1. The Preparation, Morphology and Unit Cells of Three Allomorphs. Polymer 1982, 23 (6), 805-816. https://doi.org/10.1016/00323861(82)90138-0. 
(36) Van Krevelen, D. W.; Te Nijenhuis, K. Calorimetric Properties. In Properties of Polymers; Elsevier, 2009; pp 109-128. https://doi.org/10.1016/B978-0-08-0548197.00005-4.

(37) Lefèvre, X.; Koch, M. H. J.; Reynaers, H.; David, C. Thermal Behavior of Poly(Hexamethylene Terephthalate) Oligomers. I. Melting Behavior and Morphology of the Crystalline Phase. J. Polym. Sci. Part B Polym. Phys. 1999, 37 (1), 1-18. $\quad$ https://doi.org/10.1002/(SICI)1099-0488(19990101)37:1<1::AIDPOLB1>3.0.CO;2-B.

(38) Palmer, A.; Poulin-Dandurand, S.; Revol, J.-F.; Brisse, F. Poly(Hexamethylene Terephthalate)-I. Interpretation of Its Diffraction Patterns. Eur. Polym. J. 1984, 20 (8), 783-789. https://doi.org/10.1016/0014-3057(84)90114-9.

(39) Matsen, M. W.; Bates, F. S. Block Copolymer Microstructures in the IntermediateSegregation Regime. J. Chem. Phys. 1997, 106 (6), 2436-2448. https://doi.org/10.1063/1.473153.

(40) Matsen, M. W.; Bates, F. S. Unifying Weak- and Strong-Segregation Block Copolymer Theories. Macromolecules 1996, 29 (4), 1091-1098. https://doi.org/10.1021/ma951138i. 